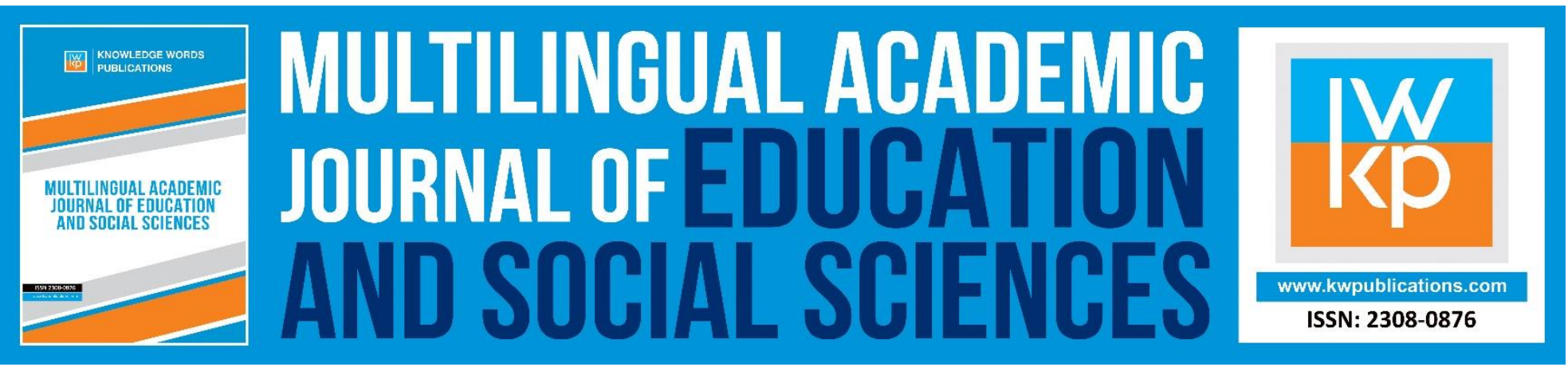

\title{
Difficulties in Learning Turkish as a Second Language by Greek-Speaking Students: A Teaching Model
}

\author{
Nikolaos Liazos \& Dimitra Markati
}

To Link this Article: http://dx.doi.org/10.46886/MAJESS/v6-i1/4506

DOI: 10.46886/MAJESS/v6-i1/4506

Received: 16 May 2018, Revised: 02 June 2018, Accepted: 09 July 2018

Published Online: 27 August 2018

In-Text Citation: (Liazos \& Markati, 2018)

To Cite this Article: Liazos, N., \& Markati, D. (2018). Difficulties in Learning Turkish as a Second Language by Greek-speaking Students: A teaching model. Multilingual Academic Journal of Education and Social Sciences, 6(1), 35-47 (in Greek).

\section{Copyright: (c) The Authors 2018}

Published by Knowledge Words Publications (www.kwpublications.com)

This article is published under the Creative Commons Attribution (CC BY 4.0) license. Anyone may reproduce, distribute, translate and create derivative works of this article (for both commercial and non-commercial purposes), subject to full attribution to the original publication and authors. The full terms of this license may be seen at: http://creativecommons.org/licences/by/4.0/legalcode

Vol. 6, No. 1, 2018, Pg. 35- 47

https://kwpublications.com/journals/journaldetail/MAJESS

JOURNAL HOMEPAGE

Full Terms \& Conditions of access and use can be found at https://kwpublications.com/pages/detail/publication-ethics 


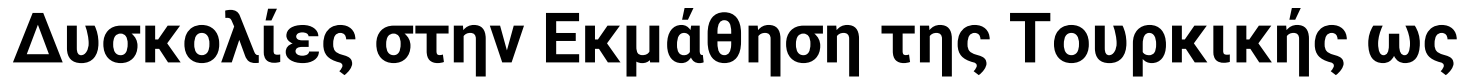

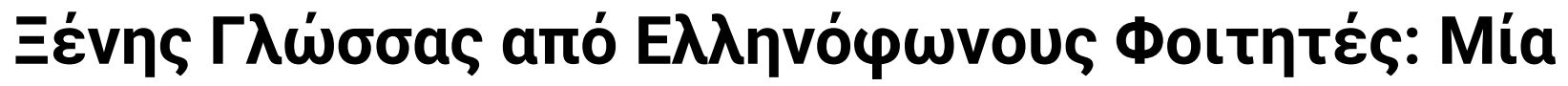

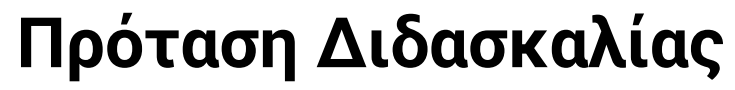

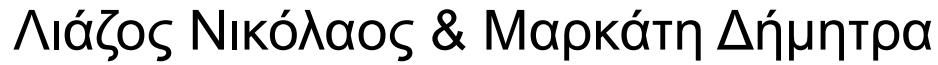

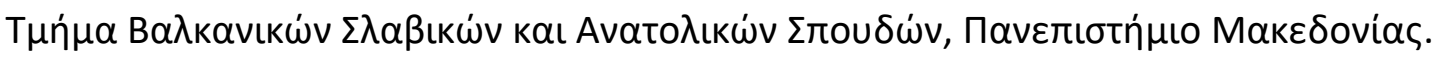

\begin{abstract}
This paper explores the difficulties that Greek-speaking students are facing while they are learning the Turkish language as a foreign one. These difficulties can be mainly found in the different structure of the target language in relation to the student's native language and in the fact that they have few oral opportunities in their Greek-speaking environment. From this perspective, the support of oral communication skills represents one of the most important points that the teaching process must deal with. By having already analyzed the recent modern methods of productive skills of verbal communication on the Turkish language as foreign language and by taking into consideration the lack of relevant complete activities in the using learning textbooks, the formalization of a specific teaching proposal is being attempted. By using a narrative text of a Turkish-speaking textbook as a reference point for the Turkish language learning as a foreign language for foreign language speakers, which is been usually used during the teaching of Turkish language at the Greek Higher Education it is been proposed a complete teaching model of the verbal communication with activities which are aiming to cover the Greekspeaking students' specific learning needs.
\end{abstract}

Keywords: Turkish as Foreign Language, Learning Difficulties, Verbal Communication, Teaching Process.

\section{Пвріं $\eta \Psi \eta$}

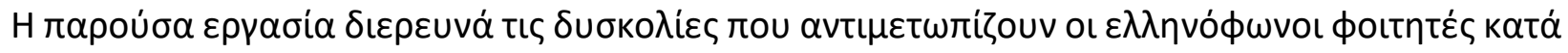

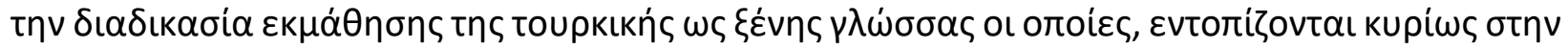

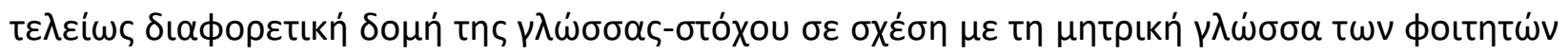

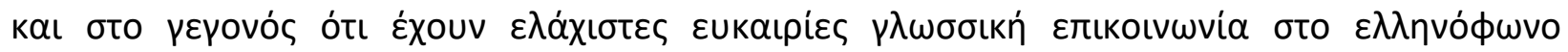

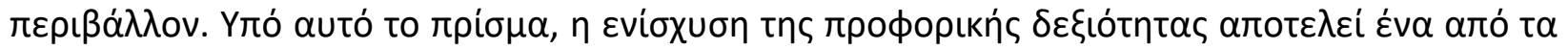

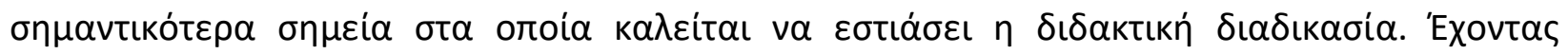

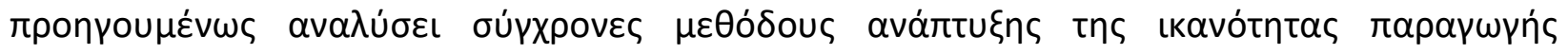

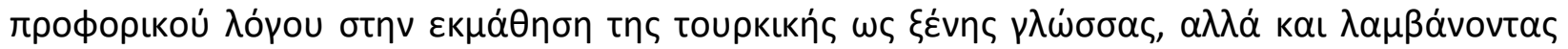




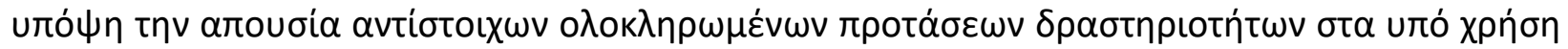

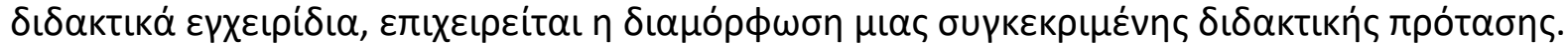

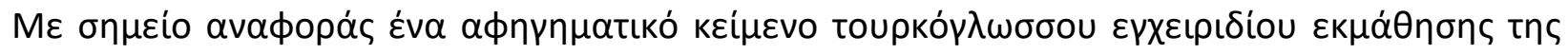

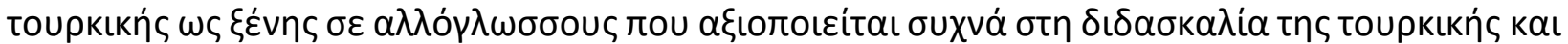

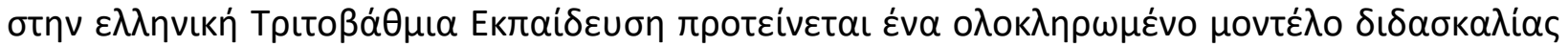

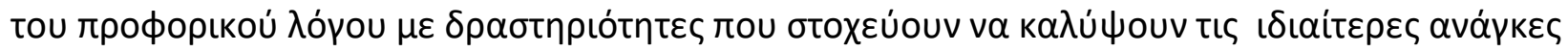

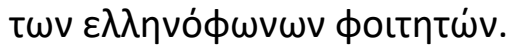

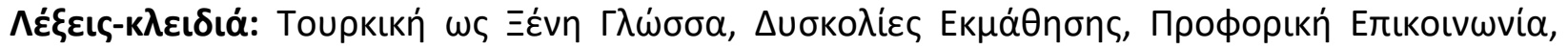

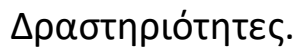

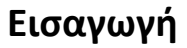

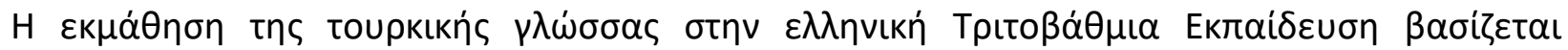

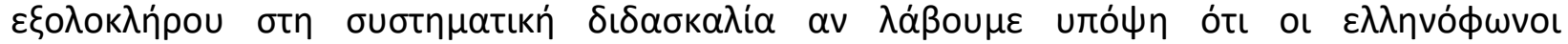

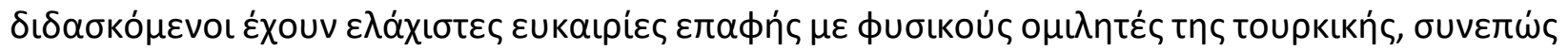

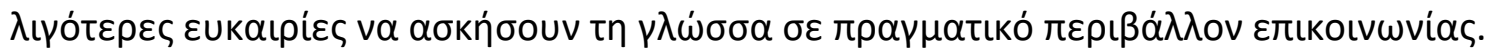

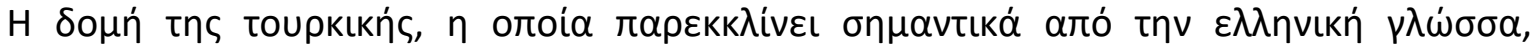

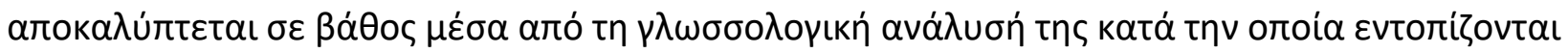

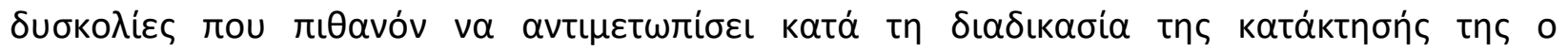
$\varepsilon \lambda \lambda \eta v o ́ \phi \omega v o \varsigma$ фoltntńs.

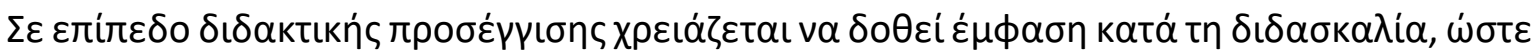

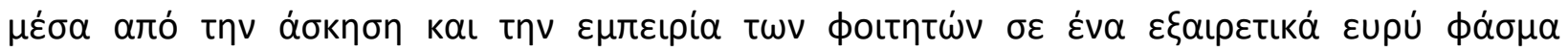

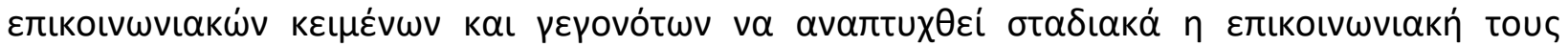

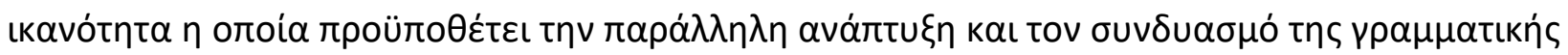

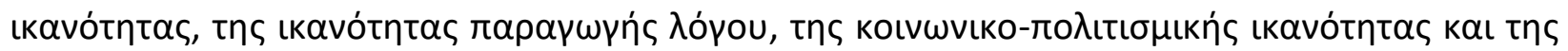

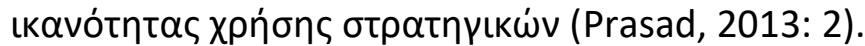

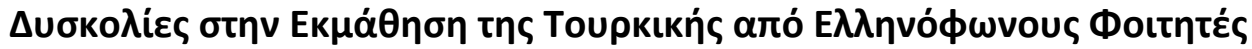

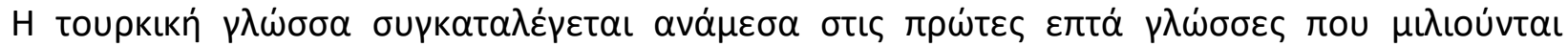

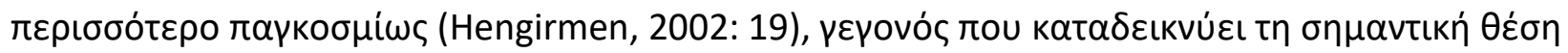

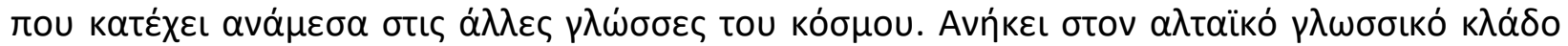

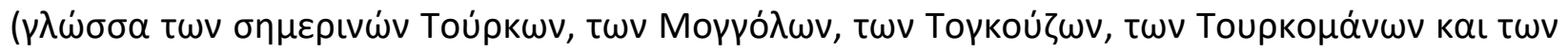

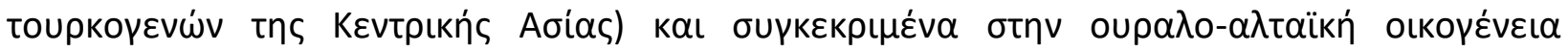

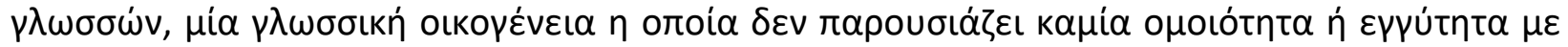

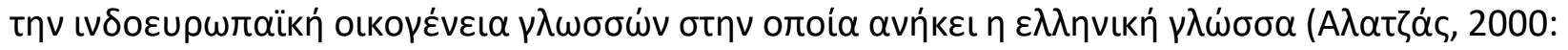

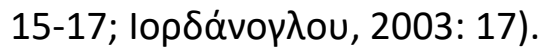

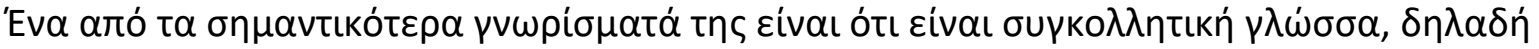

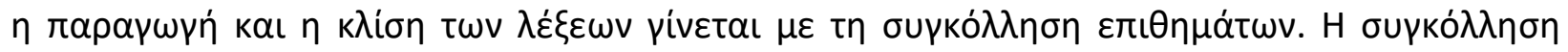

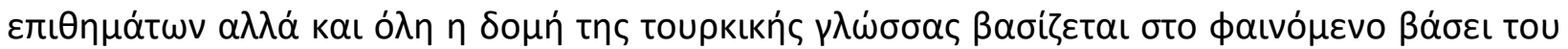

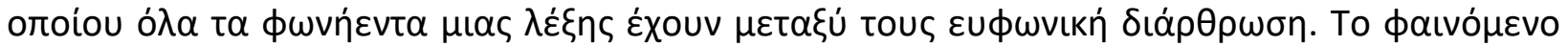

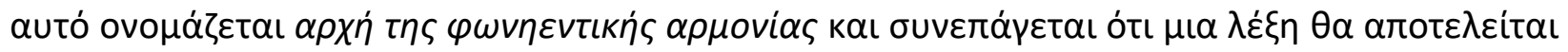




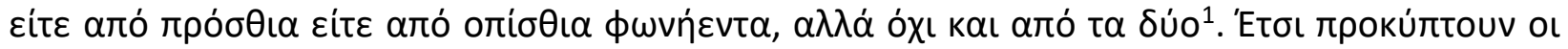

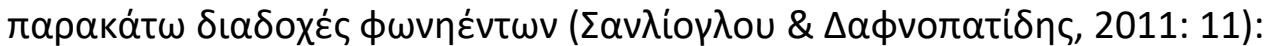

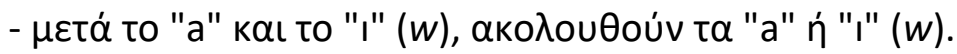

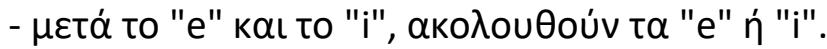

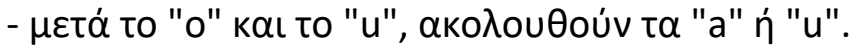

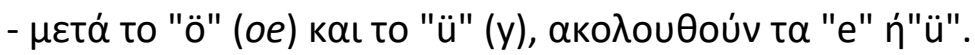

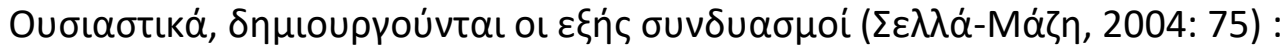

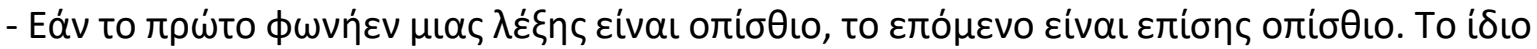

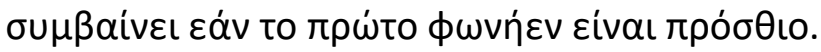

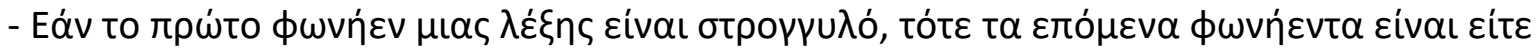

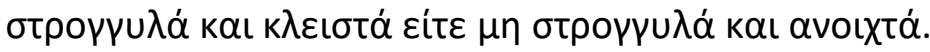

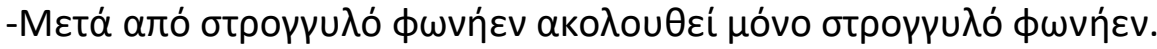

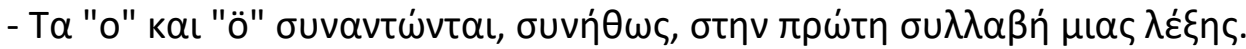

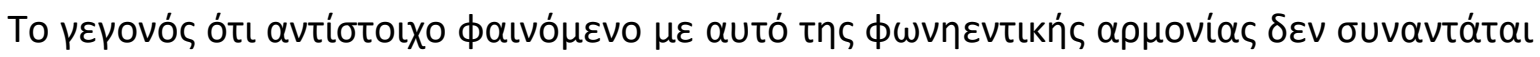

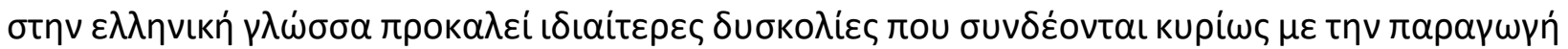

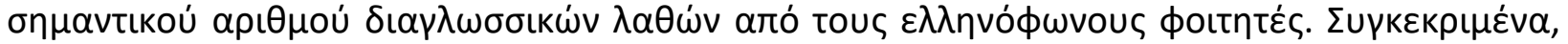

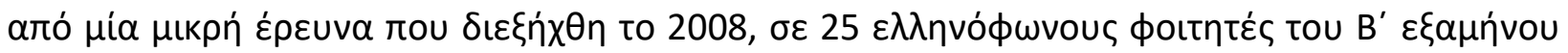

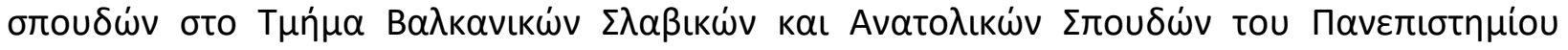

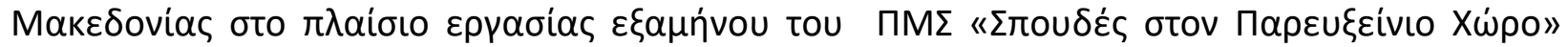

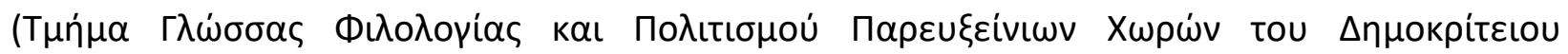

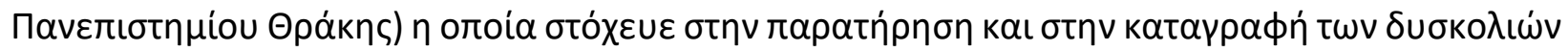

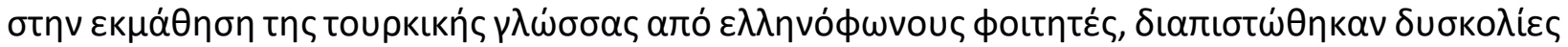

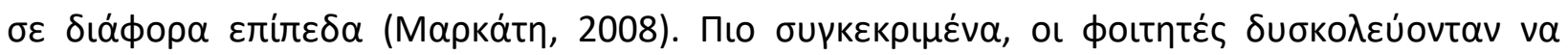

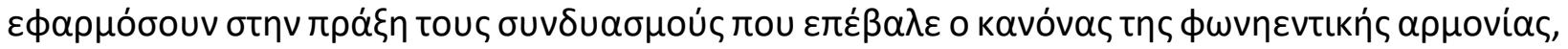

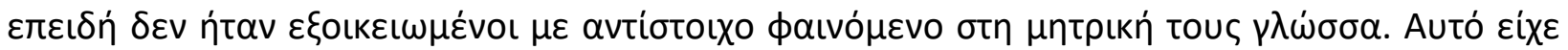

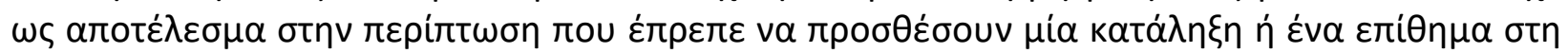

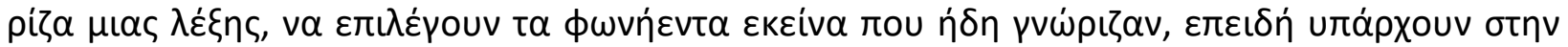

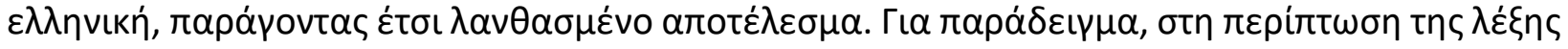

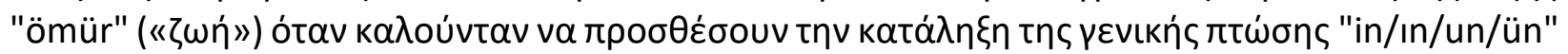

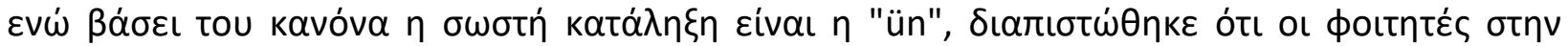

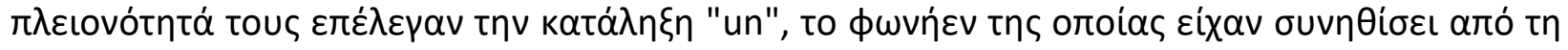

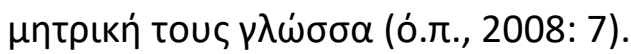

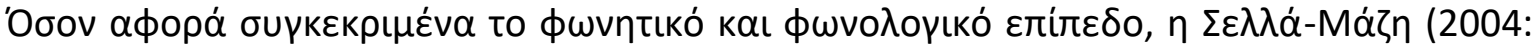

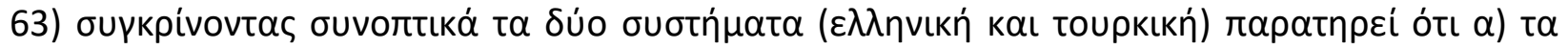

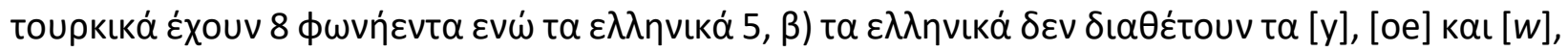

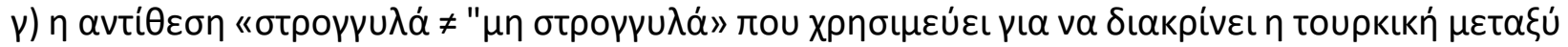

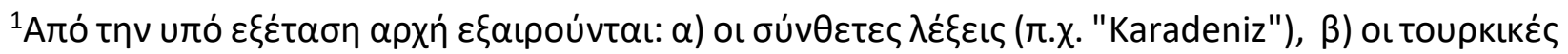

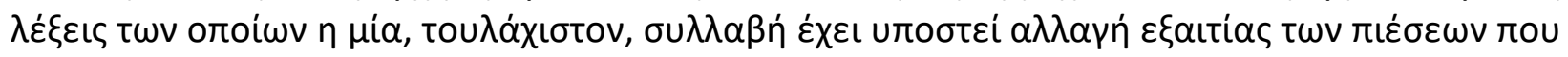

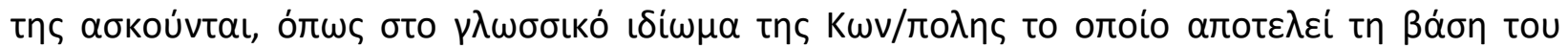

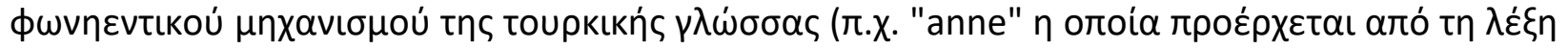

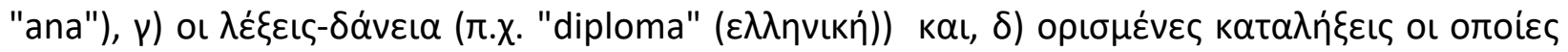

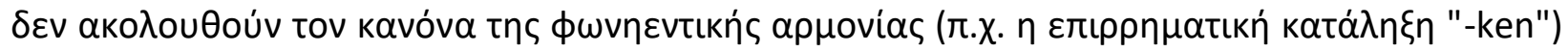

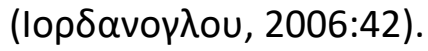




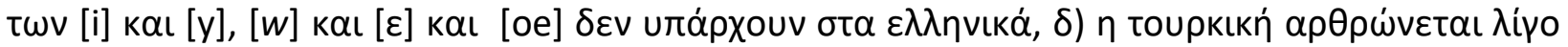

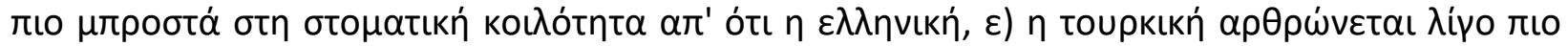

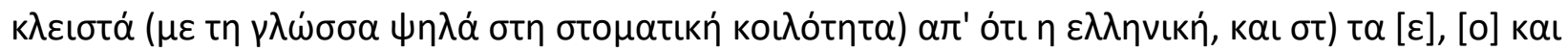

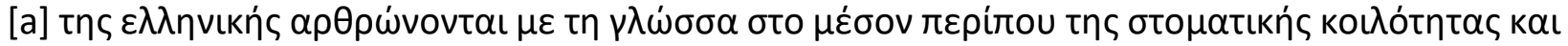

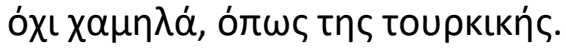

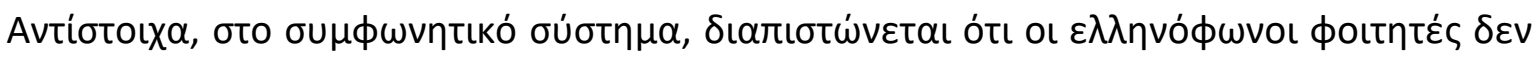

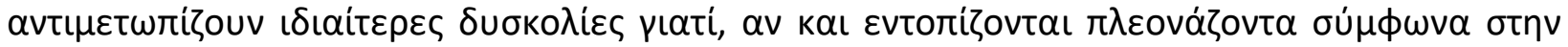

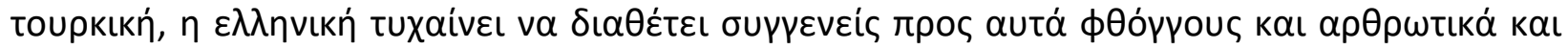

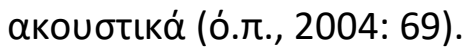

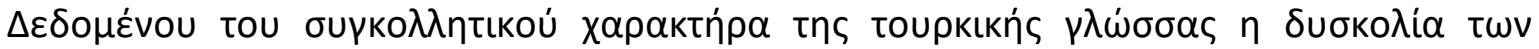

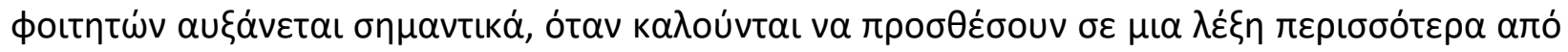

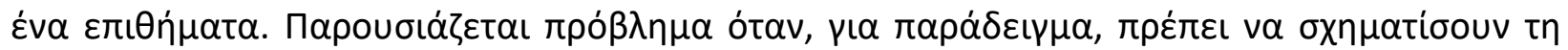

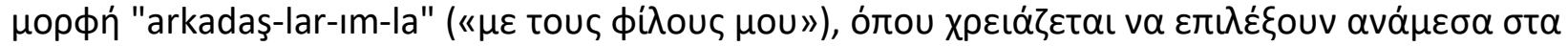

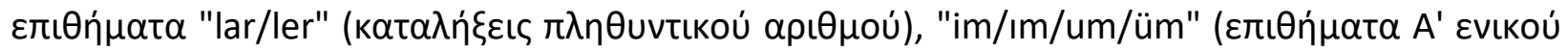

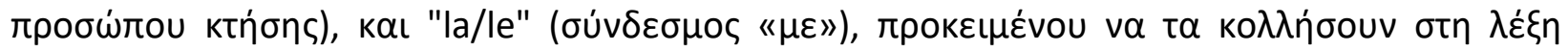

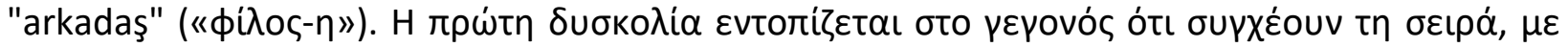

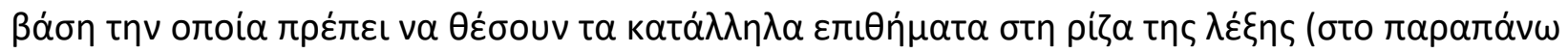

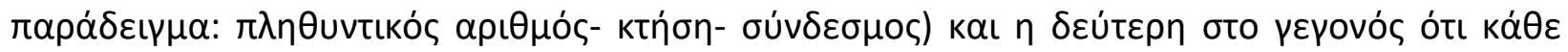

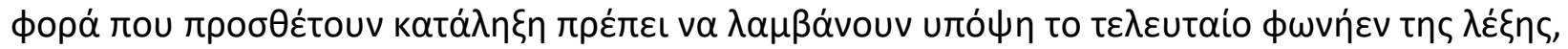

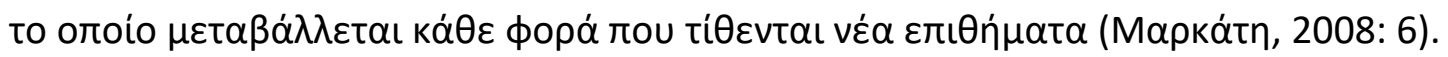

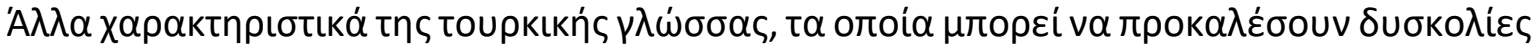

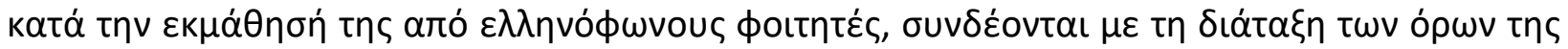

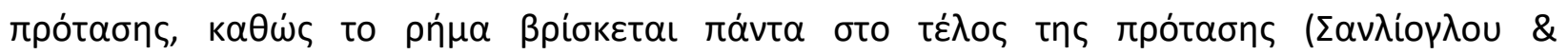

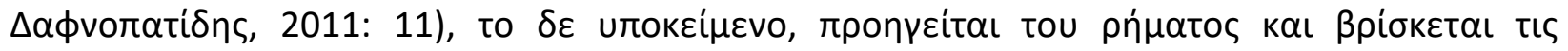

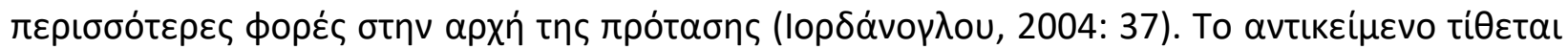

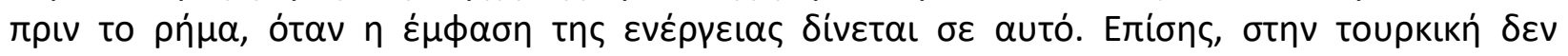

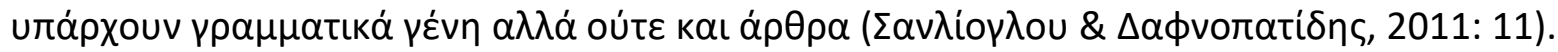

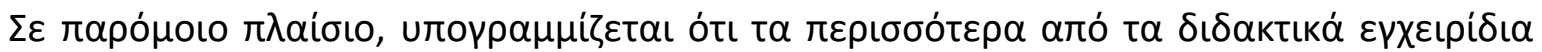

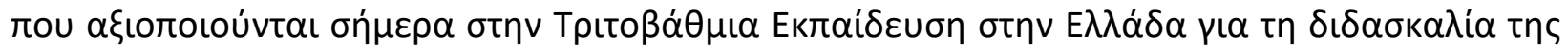

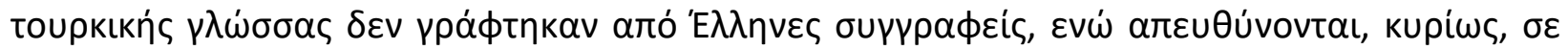

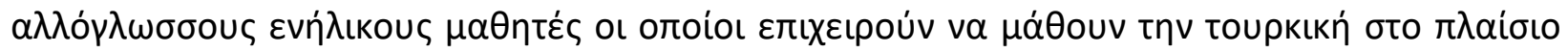

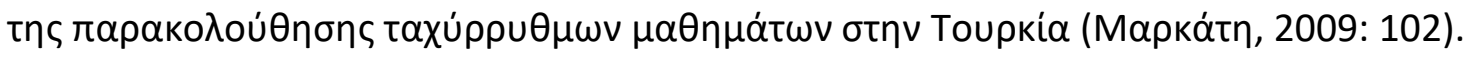

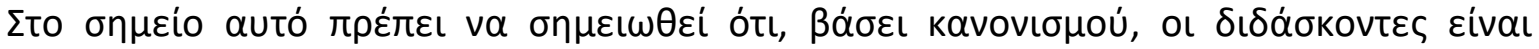

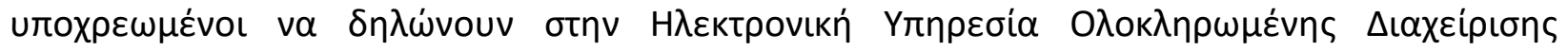

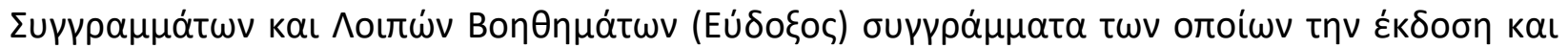

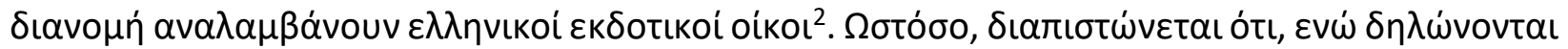

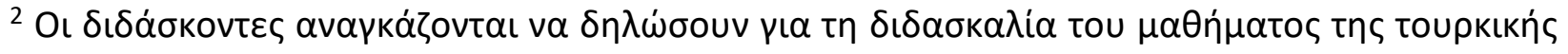

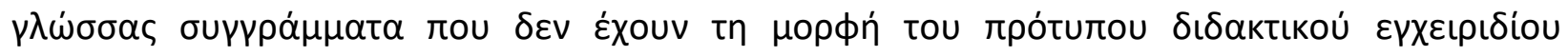

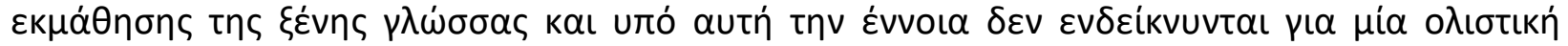

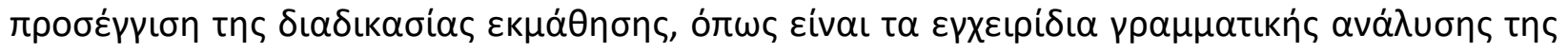

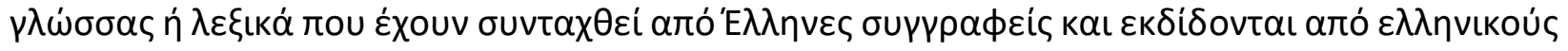

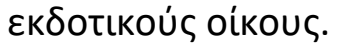




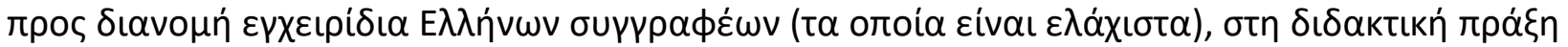

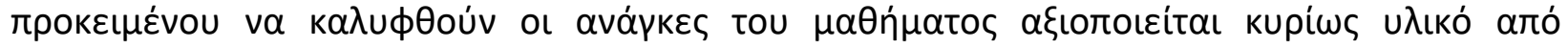

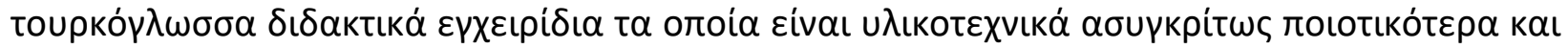

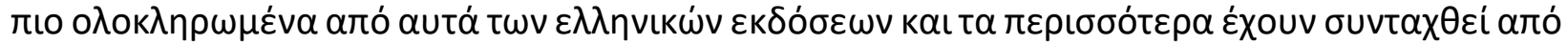

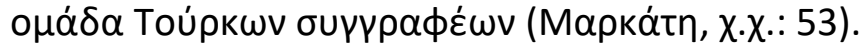

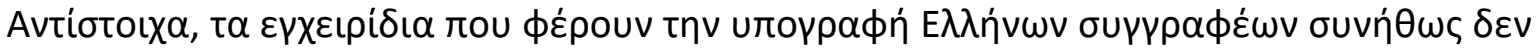

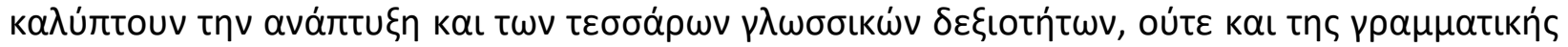

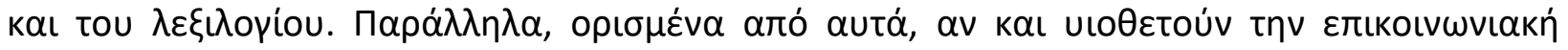

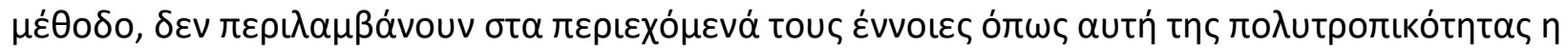

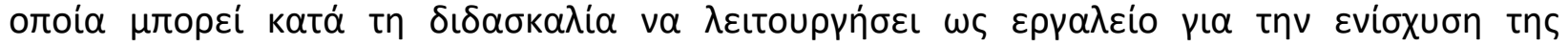

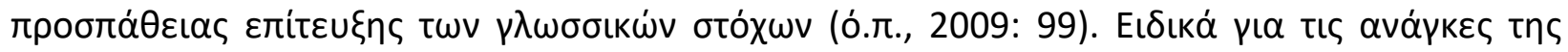

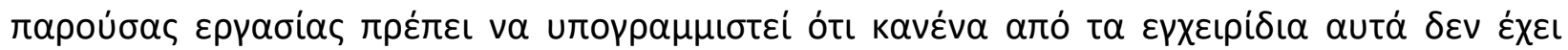

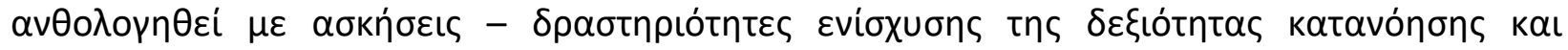

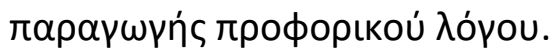

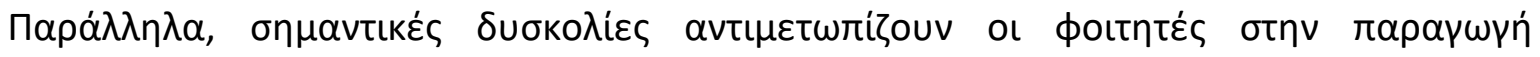

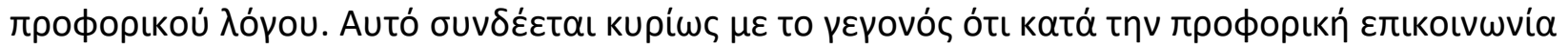

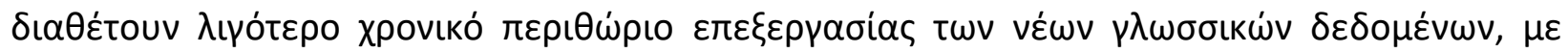

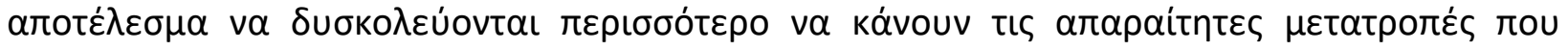

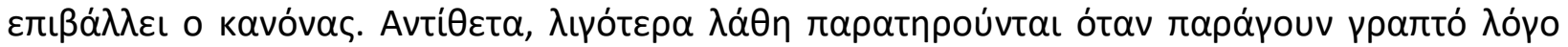
(Марка́tп, 2009: 100).

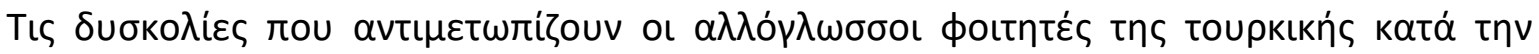

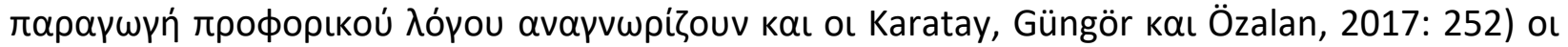

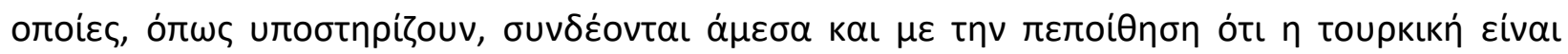

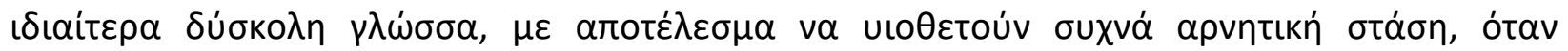

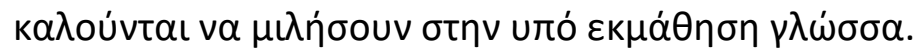

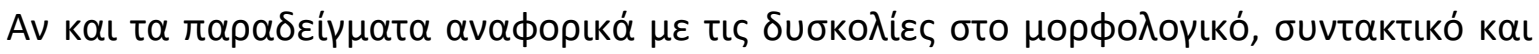

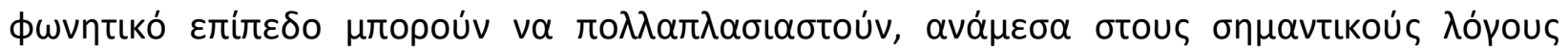

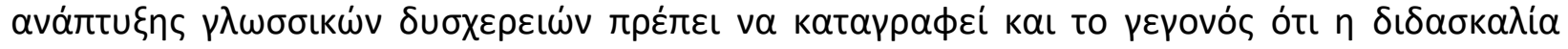

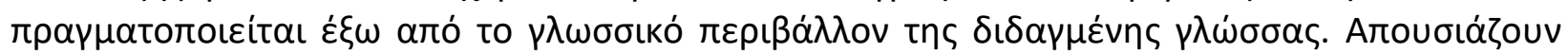
$\delta \eta \lambda \alpha \delta$

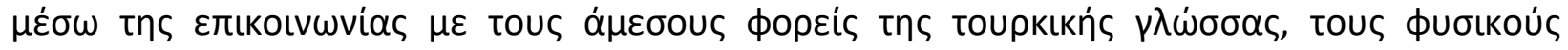

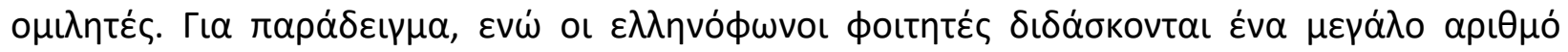

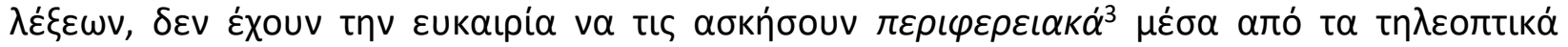

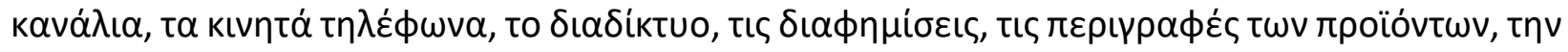

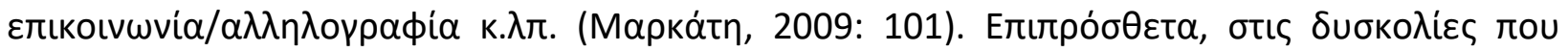

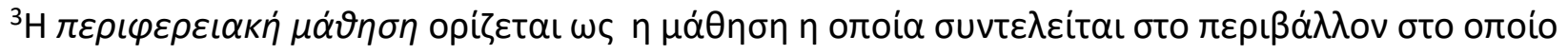

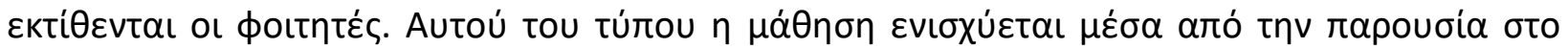

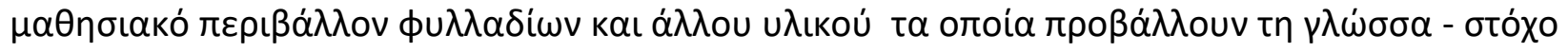

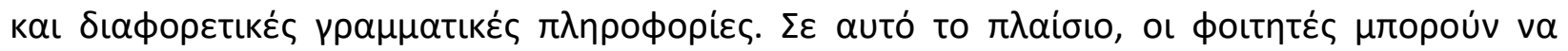

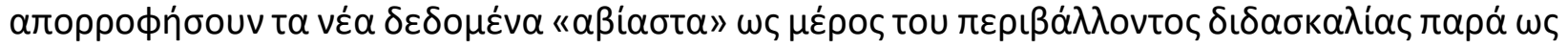

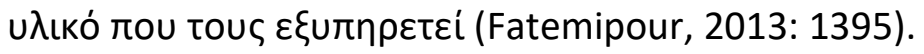


MULTILINGUAL ACADEMIC JOURNAL OF EDUCATION AND SOCIAL SCIENCES

Vol. 6 No. 1, 2018, E-ISSN: 2308-0876 @ 2018 KWP

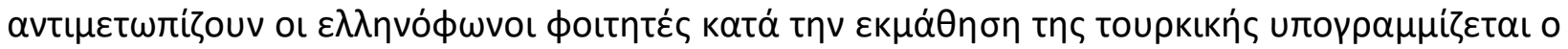

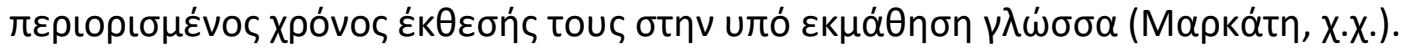

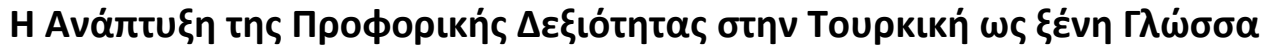

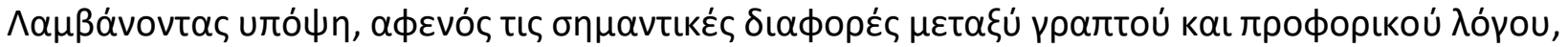

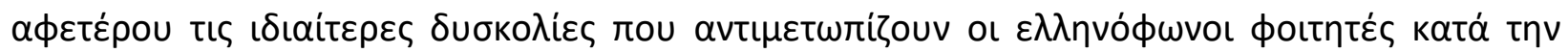

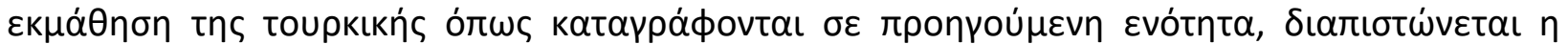

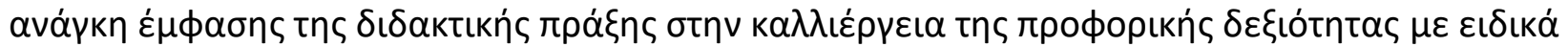

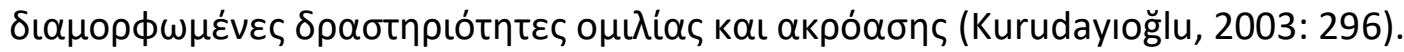

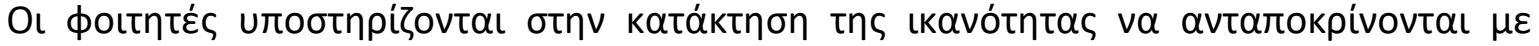

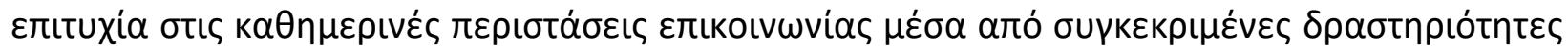

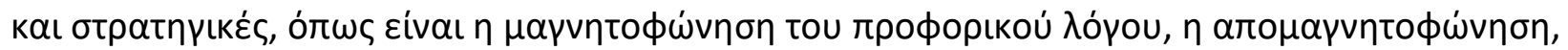

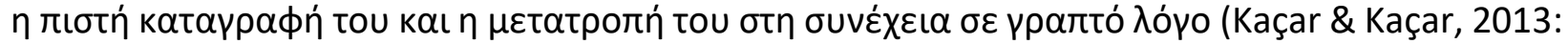

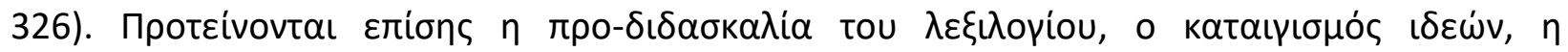

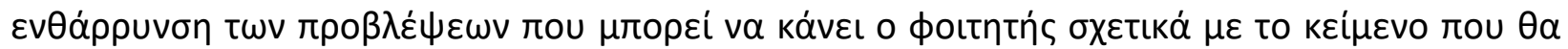

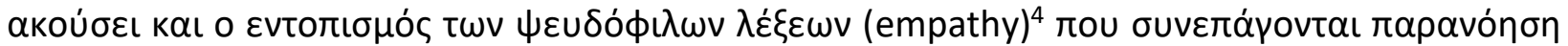

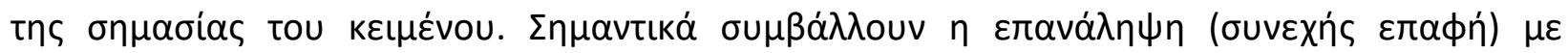

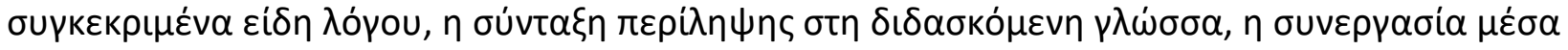

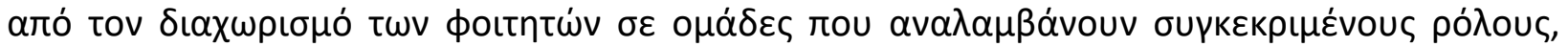

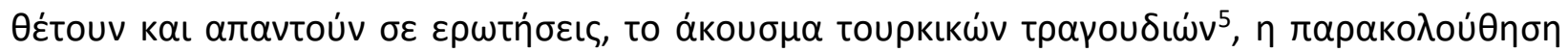

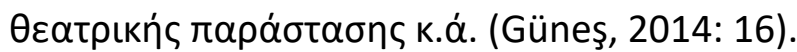

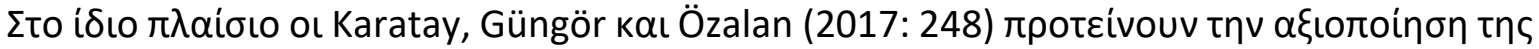

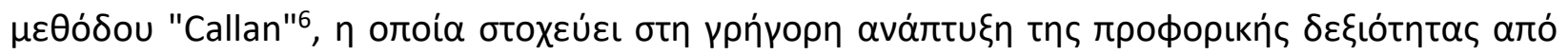

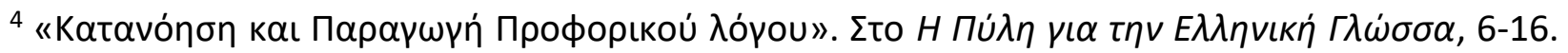

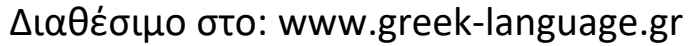

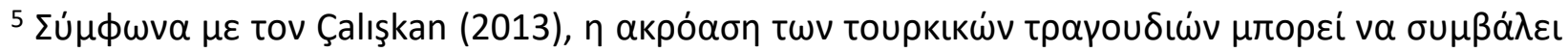

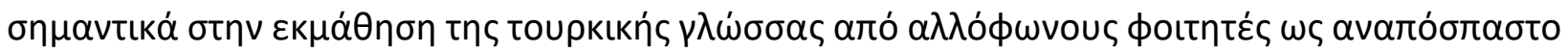

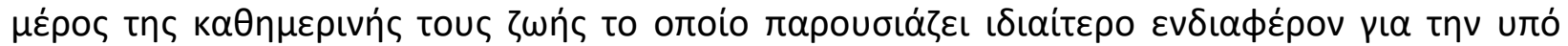

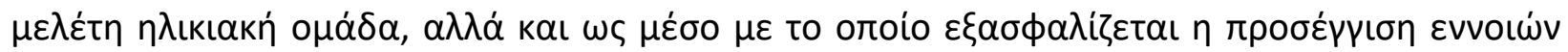

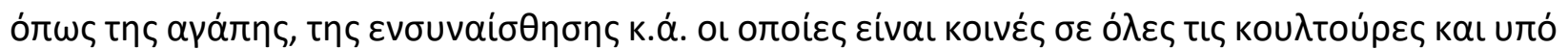

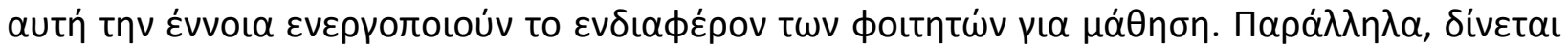

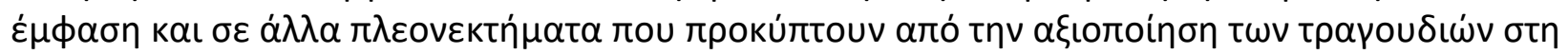

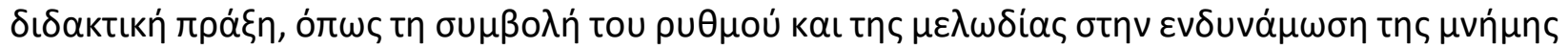

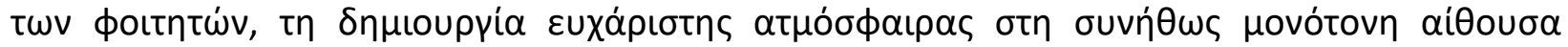

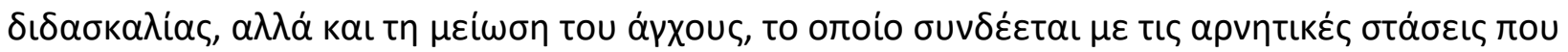

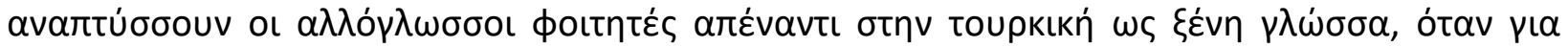

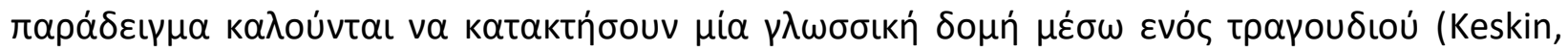
2011: 379) .

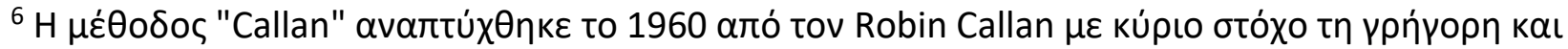

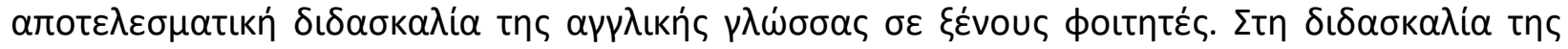

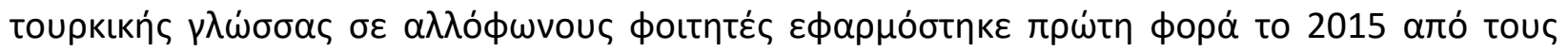

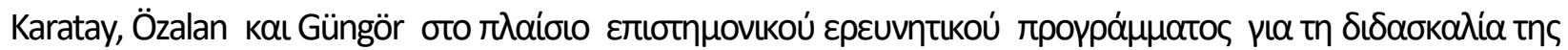
тоuркщńs tou Пaverıơnuíou Abant İzzet Baysal (Karatay, Güngör \& Özalan, 2017: 259). 


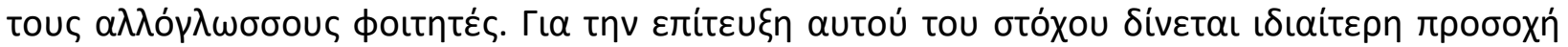

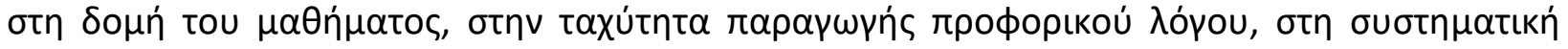

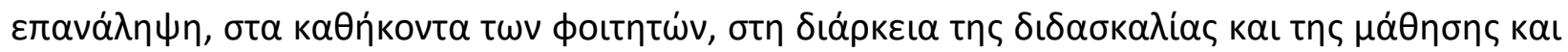

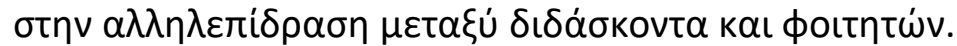

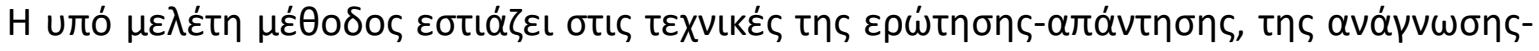

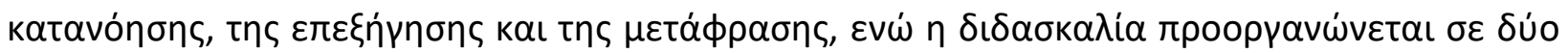

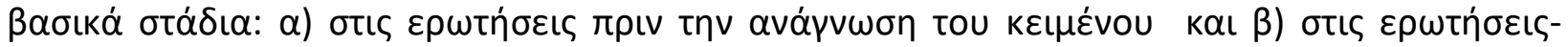

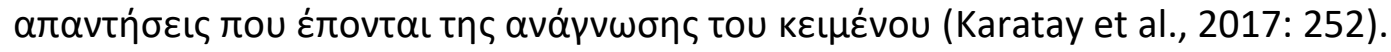

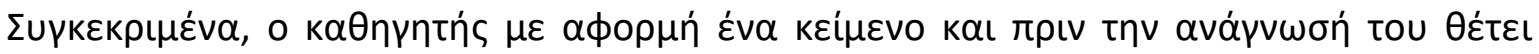

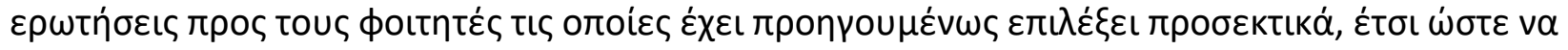

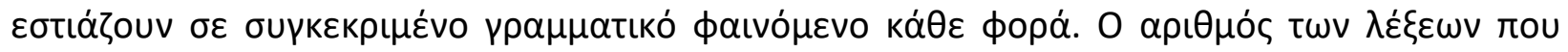

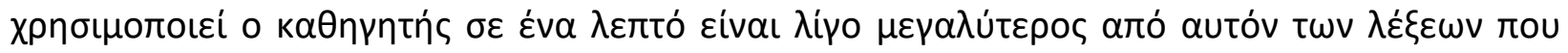

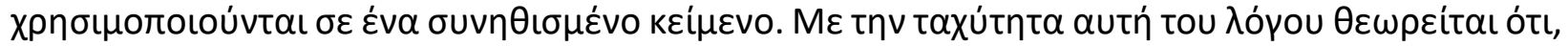

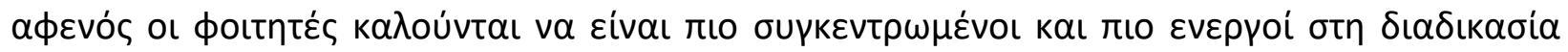

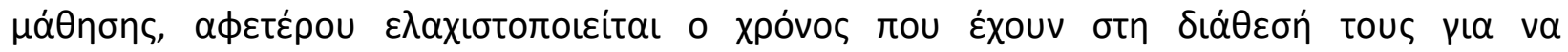

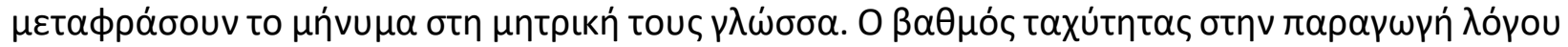

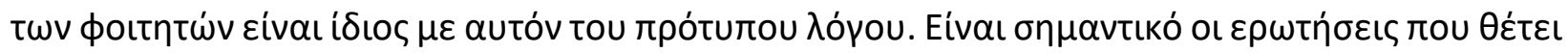

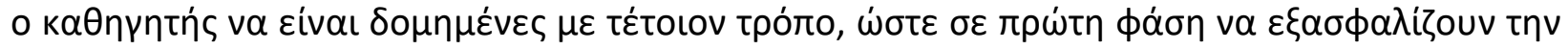

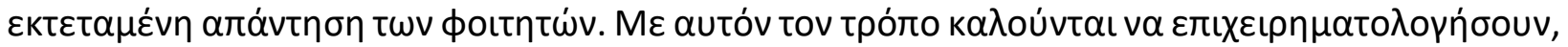

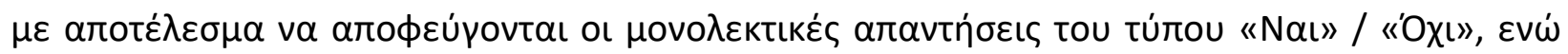

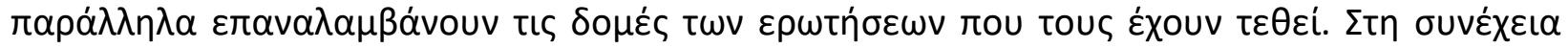

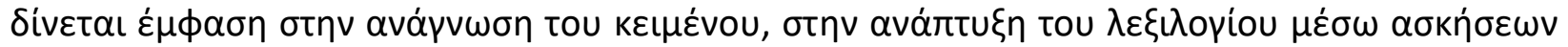

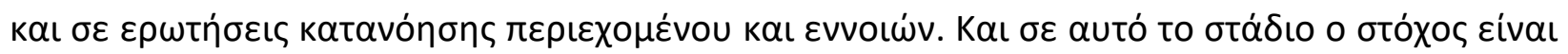

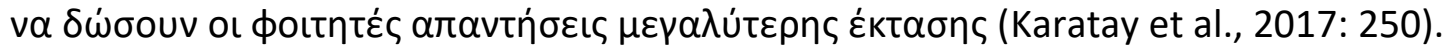

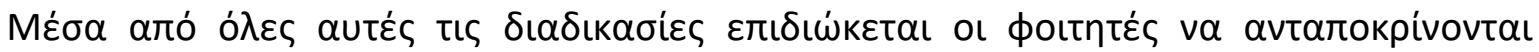

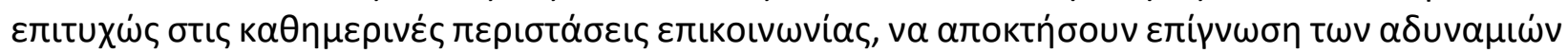

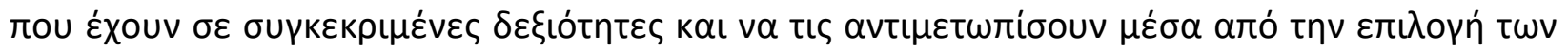

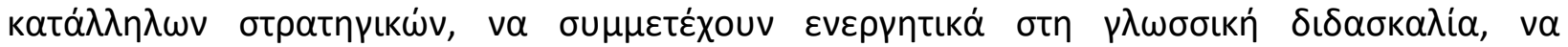

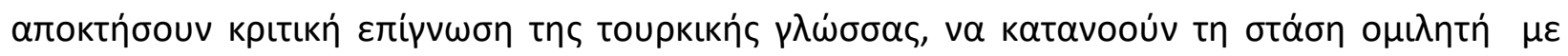

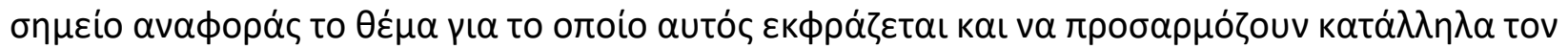

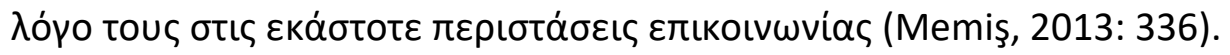

\section{H $\pi \rho o ́ \tau \alpha \sigma \eta ~ \delta เ \delta \alpha \sigma \kappa \alpha \lambda i \alpha \varsigma$

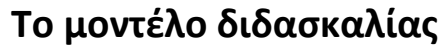

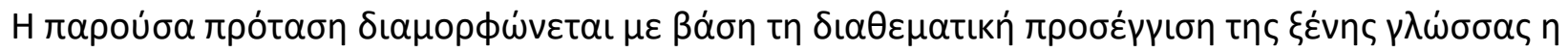

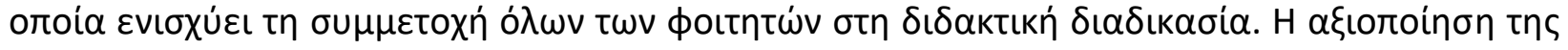

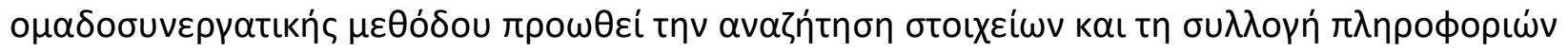

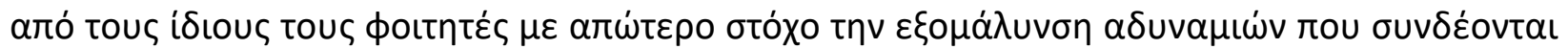

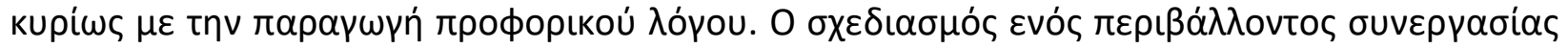

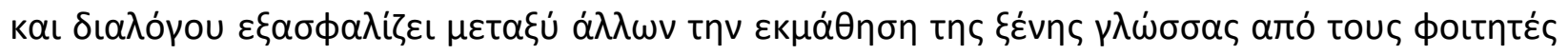

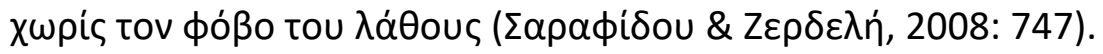

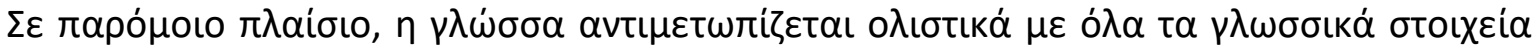

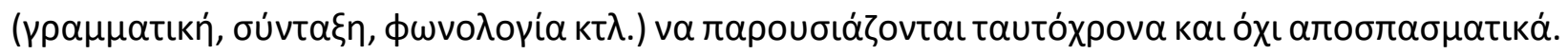

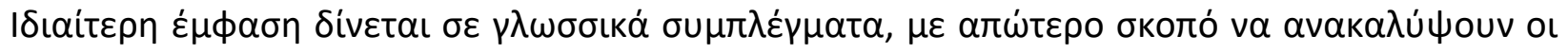


MULTILINGUAL ACADEMIC JOURNAL OF EDUCATION AND SOCIAL SCIENCES

Vol. 6 No. 1, 2018, E-ISSN: 2308-0876 @ 2018 KWP

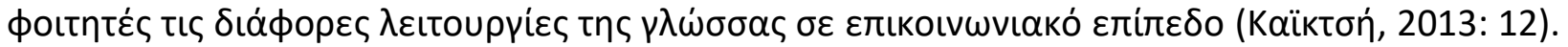

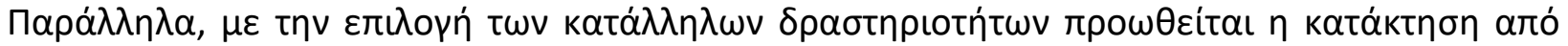

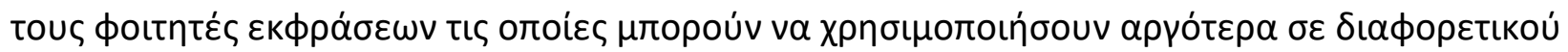

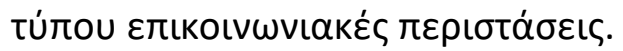

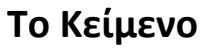

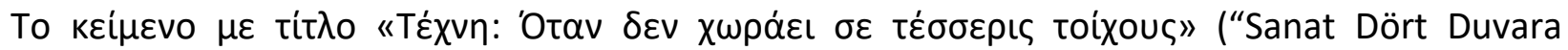

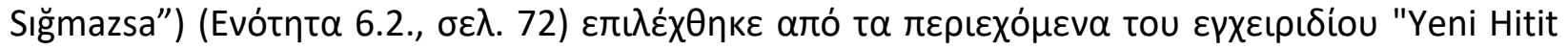
Yabancılar için Türkçe - Ders Kitabı 2" (Kurt, Aygün, Leblebici, Coşkun, 2008) rou

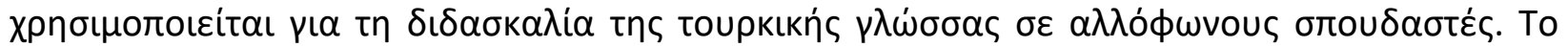

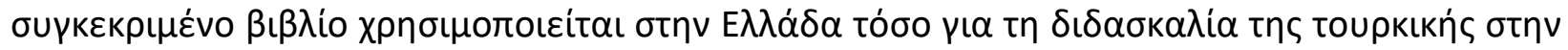

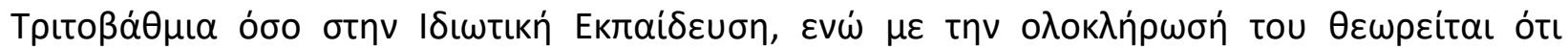

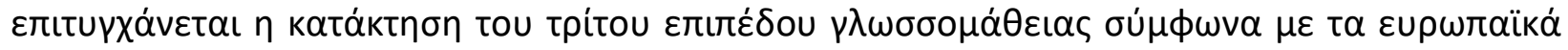

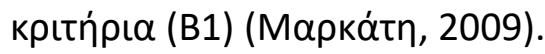

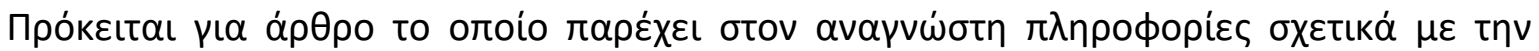

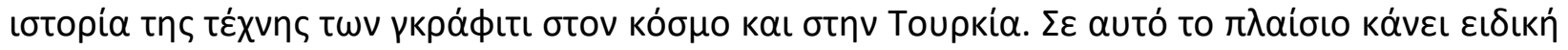

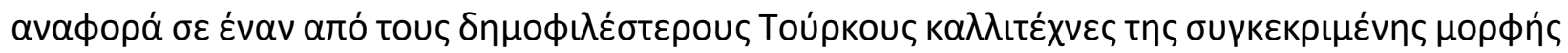

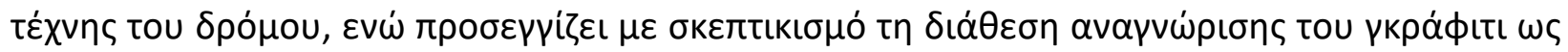
$\mu \mathrm{l} \alpha \varsigma$ a

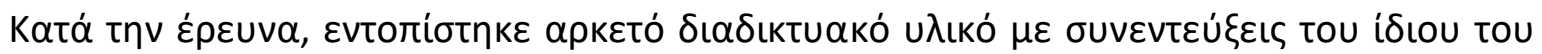

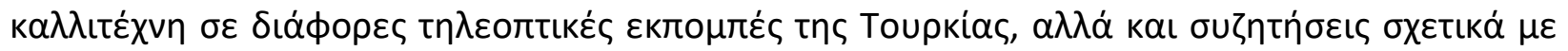

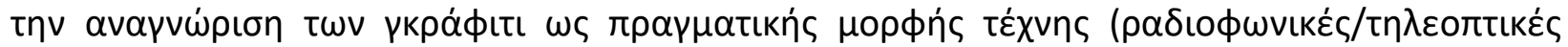

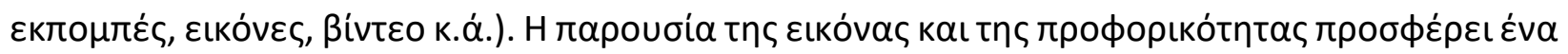

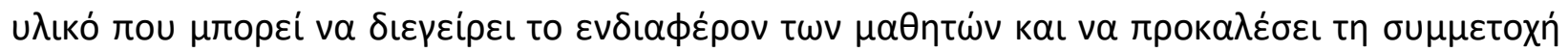
тouৎ (Ká $\lambda \phi \alpha \varsigma, 1990: 24)$.

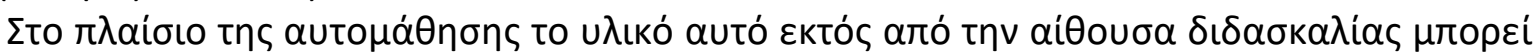

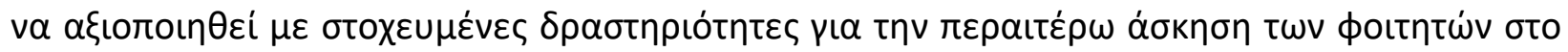

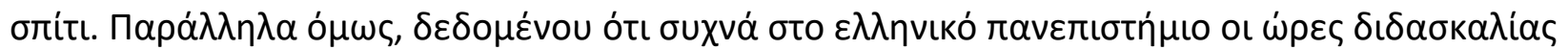

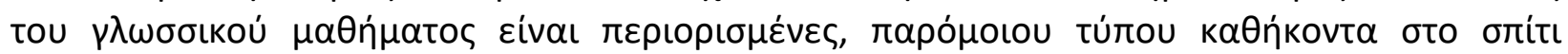

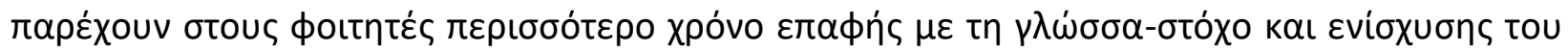

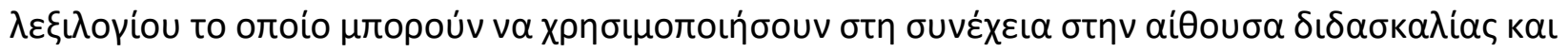

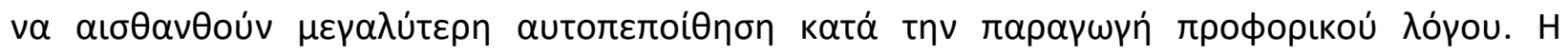

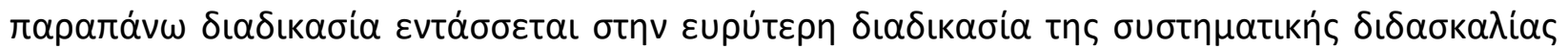

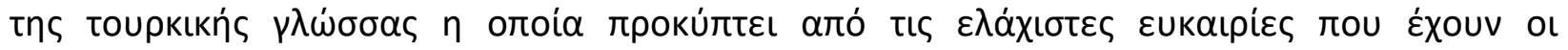

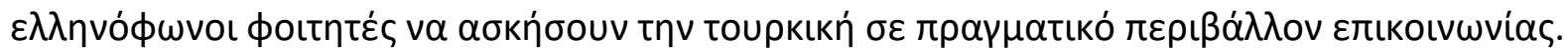

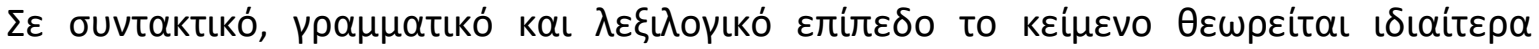

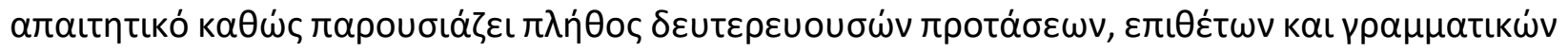

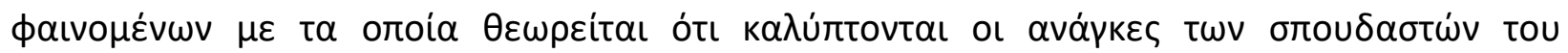

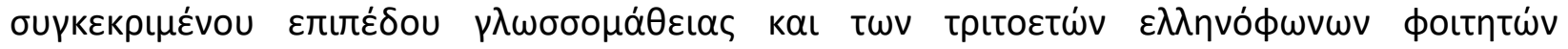
avtíбtolx $\alpha$.

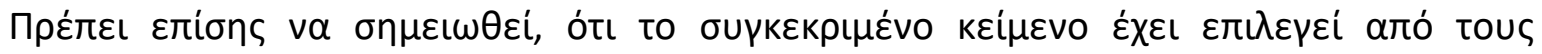

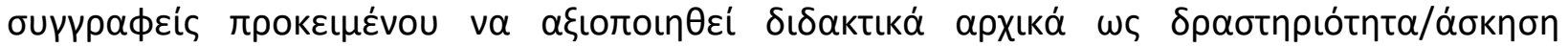

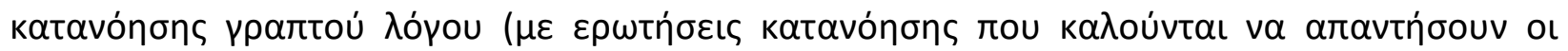

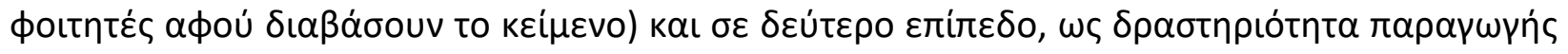




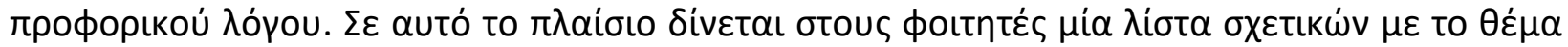

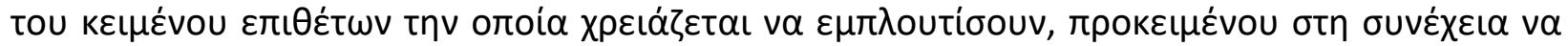

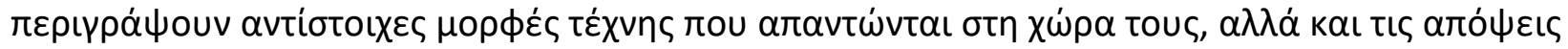

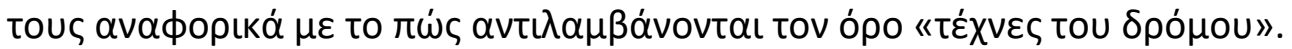

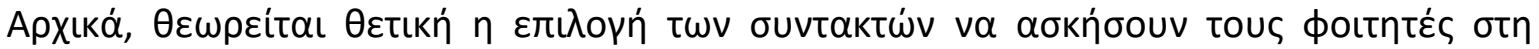

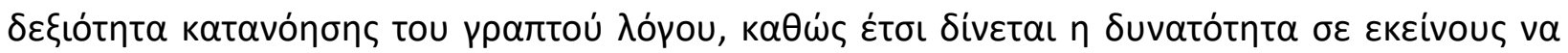

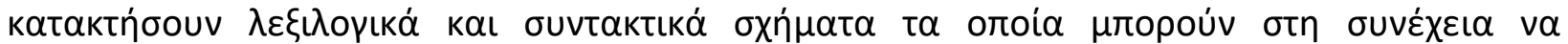

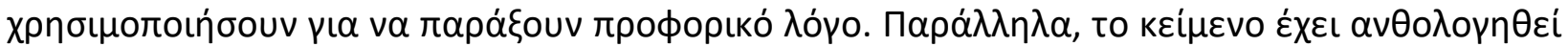

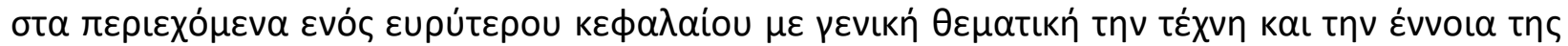

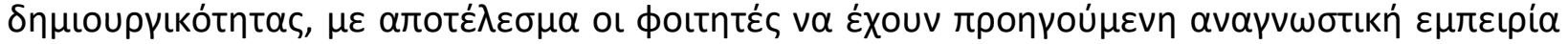

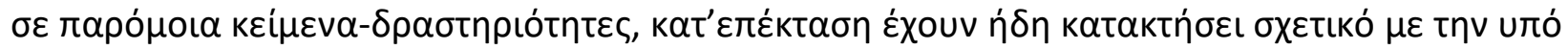

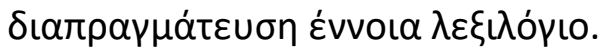

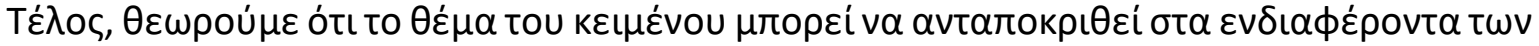

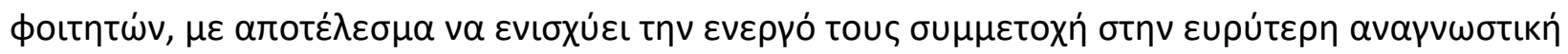

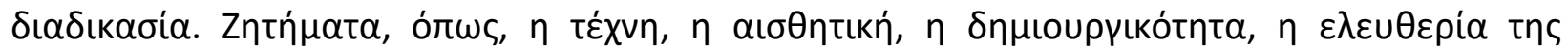

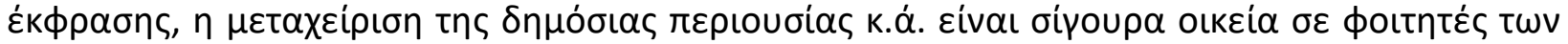

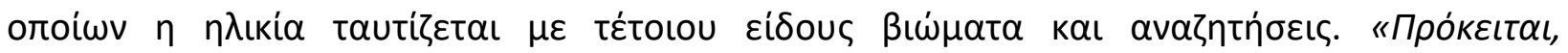

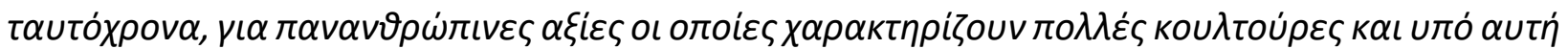

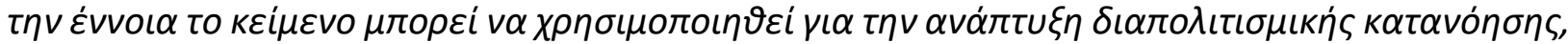

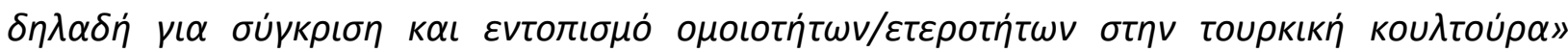

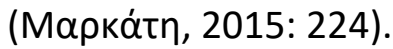

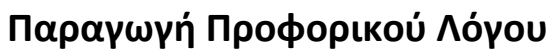

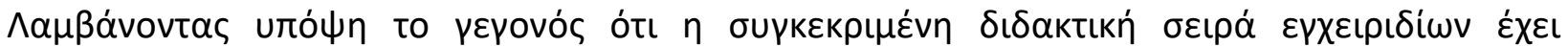

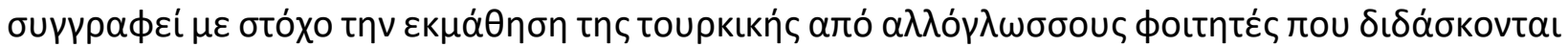

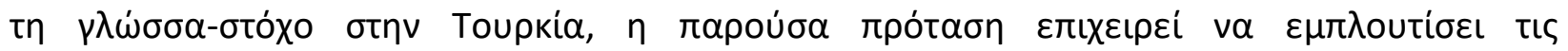

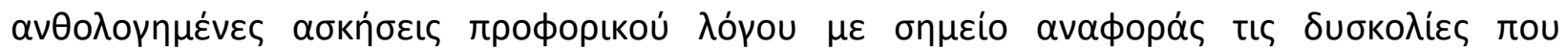

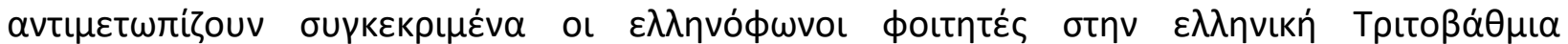

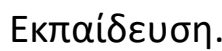

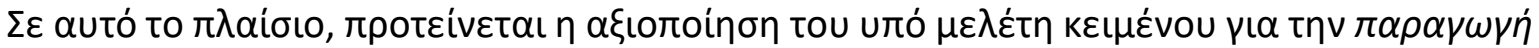

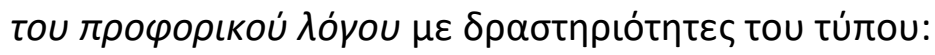

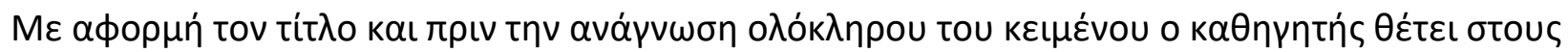

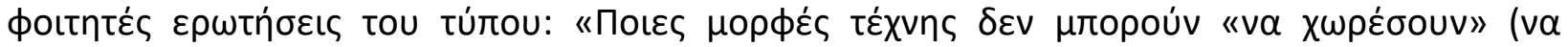

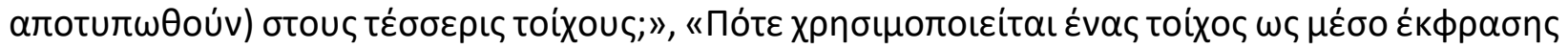

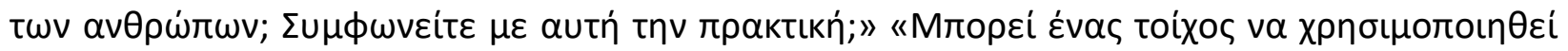

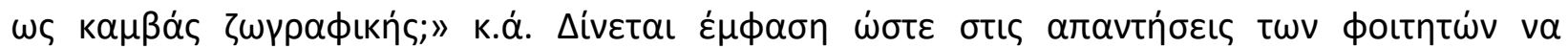

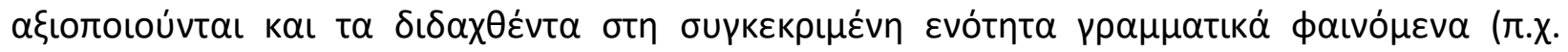
$\mu \varepsilon \tau \alpha \beta \iota \beta \alpha \sigma \tau \iota \alpha \dot{\alpha} \rho \operatorname{\mu n} \alpha \tau)$.

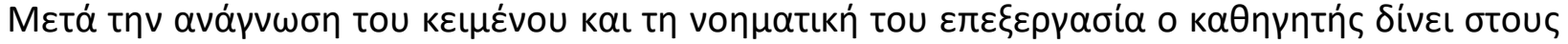

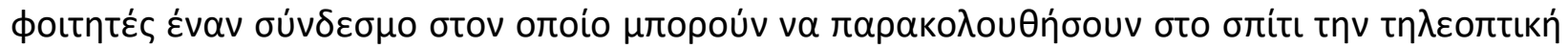

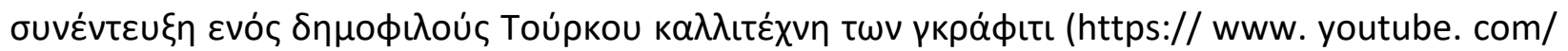
watch ?v=_nCBn3SqhYQ).

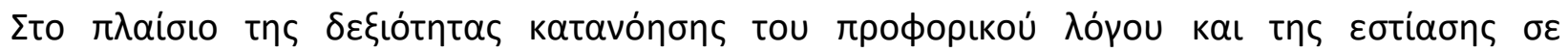

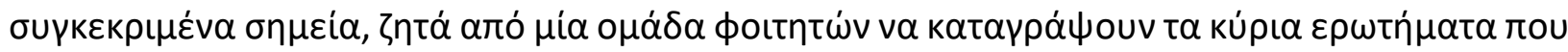




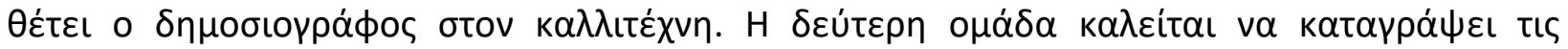

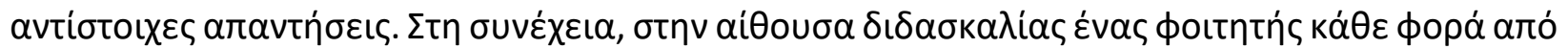

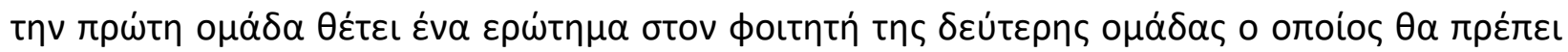

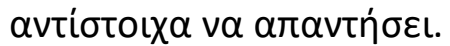

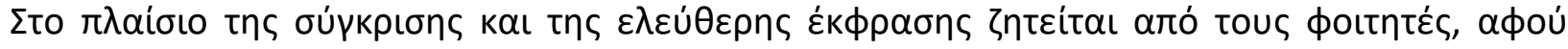

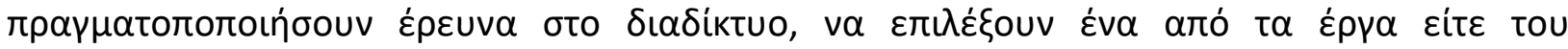

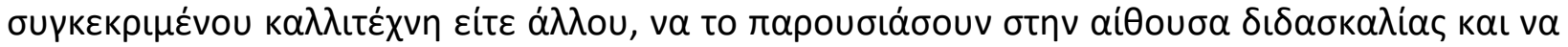

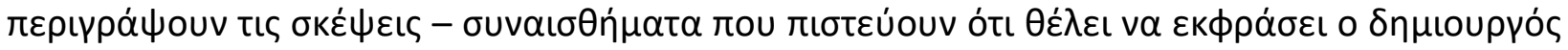

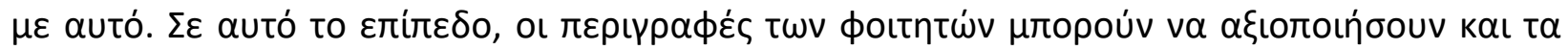

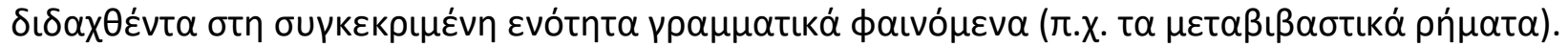

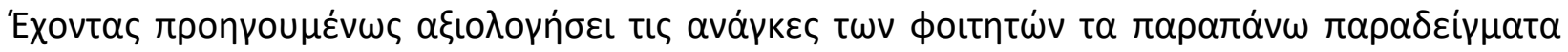
$\mu \pi \circ \rho \circ u^{2} v \alpha \pi \circ \lambda \lambda \alpha \pi \lambda \alpha \sigma \iota \alpha \sigma \tau o u ́ v$.

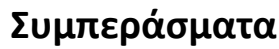

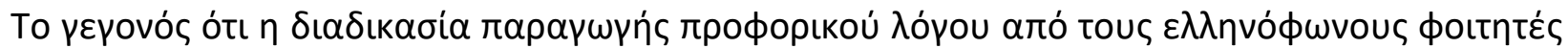

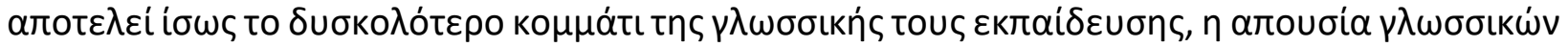

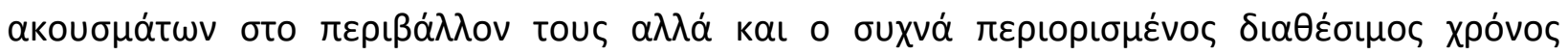

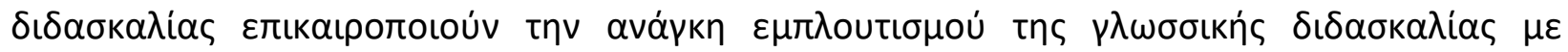

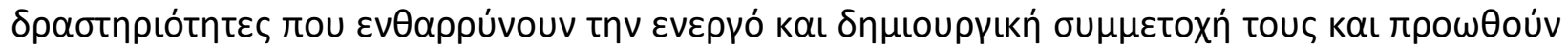

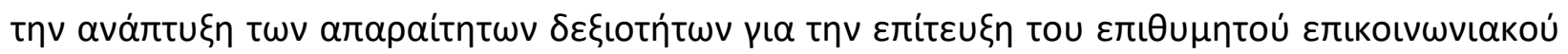

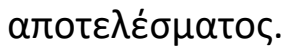

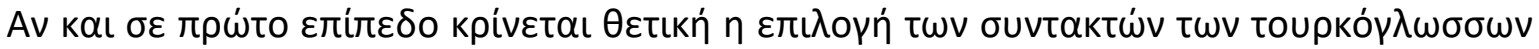

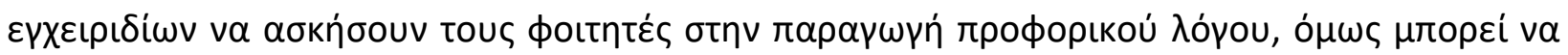

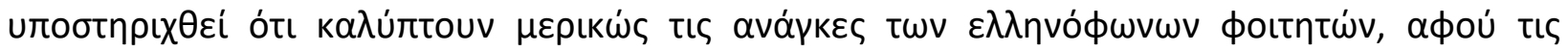

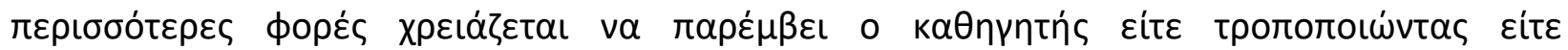

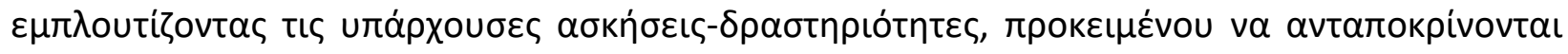

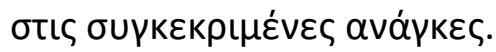

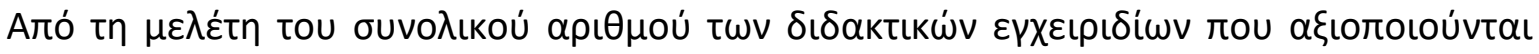

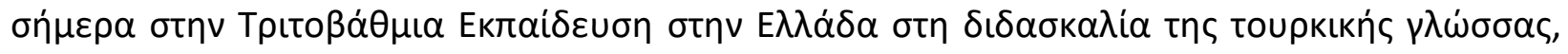

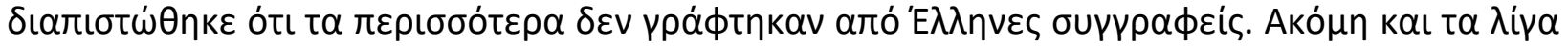

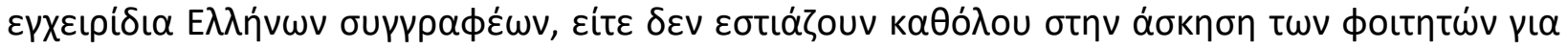

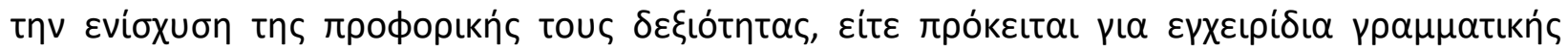

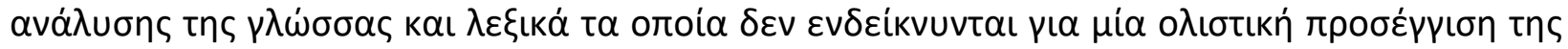

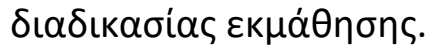

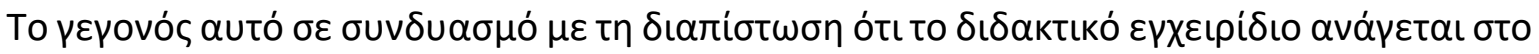

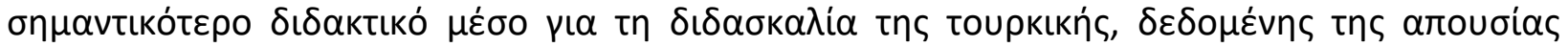

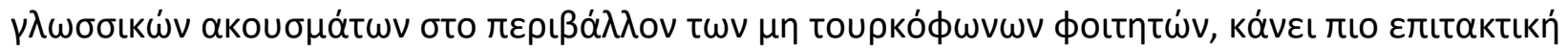

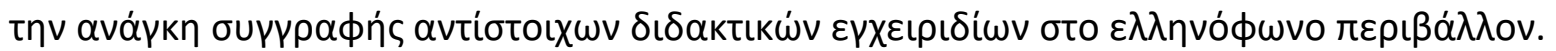

\section{References}

Barın, E. (1994). Yabancılara Türkçenin Öğretimi Metodu. A.Ü. TÖMER Dil Dergisi, 17, 53-56. Bekleyen, N. (2003). The Influence of Teachers and Peers on Foreign Language Classroom Anxiety. Language Journal, 3(2), 49-66. 
Çalışkan, A. (2013). "Yabancılara Türkçe Öğretiminde Müziğin Kullanımı". 2. Uluslararası Dil ve Edebiyat Konferansı "Balkanlarda Türkçe", Bildiri Kitabı II, Balaban \& Çağlayan (ed.), 14-16 Kasım 2014, Tiran: 15-24.

Doğan, C. (2012). Sistematik Yabancı Dil Öğretim Yaklaşım ve Yöntemleri. İstanbul: Ensar Neşriyat. Fatemipour, H. (2013). Peripheral Learning of English language: A Comparison Between ESL and EFL Contexts Provided for University Students. Procedia-Social and Behavioral Sciences, 93, 1394-1397.

Hengirmen, M. (2002). Türkçe Dilbilgisi. Ankara: Engin.

Kaçar, E., \& Kaçar, H. (2013). "Arnavutluk'ta Yaşayan Türk Öğrencilerin Anadildeki Problemleri". 2. Uluslararası Dil ve Edebiyat Konferansı "Balkanlarda Türkçe", Bildiri Kitabı II, Balaban \& Çağlayan (ed.), 14-16 Kasım 2014, Tiran: 322-329.

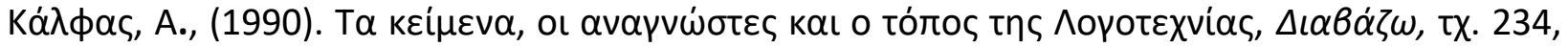
22-27.

Karatay, H., Güngör, H., \& Özalan, U. (2017). Türkçenin Yabancı Dil Olarak Öğretiminde Callan Yöntemi. International Journal of Language Academy, 5(2), 250-265.

Keskin, F. (2011). Using songs as audio materials in teaching Turkish as a foreign language. TOJET: The Turkish Online Journal of Educational Technology, 10(4), 378-383.

Kiziltan, N. (2012). Teaching Turkish through Teletandem. Procedia Social and Behavioral Sciences $46,3363-3367$.

Kurt, C., Aygün, E. N., Leblebici, E., \& Altınkaynak Ö., C. (2008). Yeni Hitit 2 Yabancılar için Türkçe Ders Kitabı. Ankara: Ankara Üniversitesi Basımevi.

Kurudayıoğlu, M. (2003). Konuşma Eğitimi ve Konuşma Becerisini Geliştirmeye Yönelik Etkinlikler. Available online at http://dergipark.gov.tr/download/article-file/156773, 287-309.

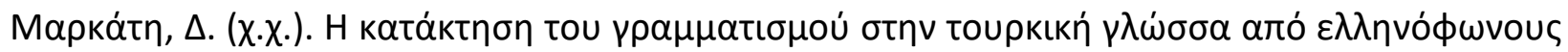

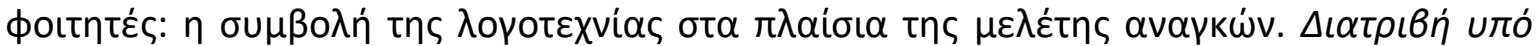

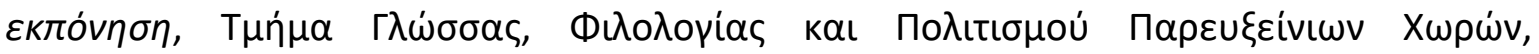

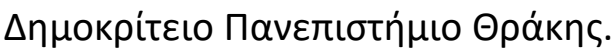

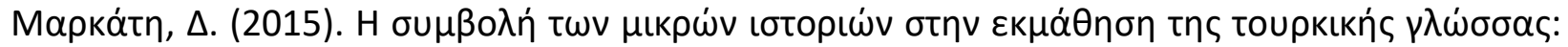

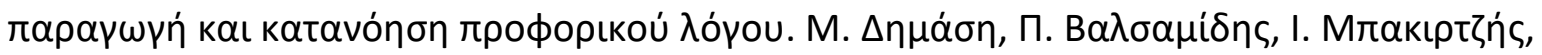

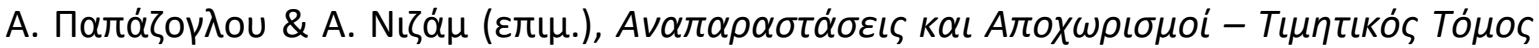

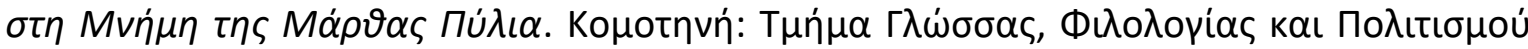

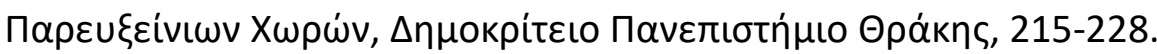

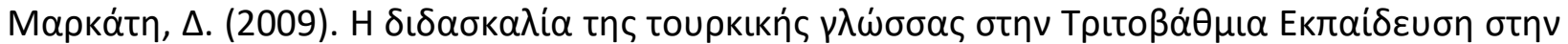

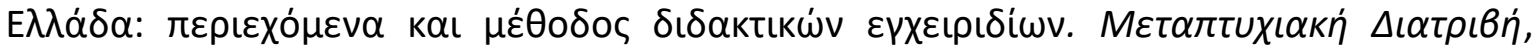

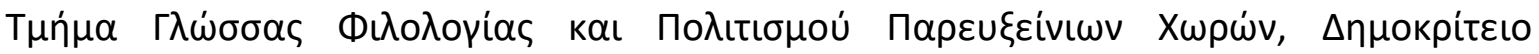

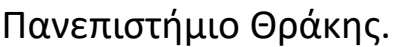

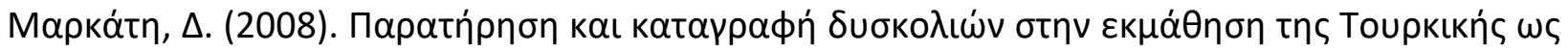

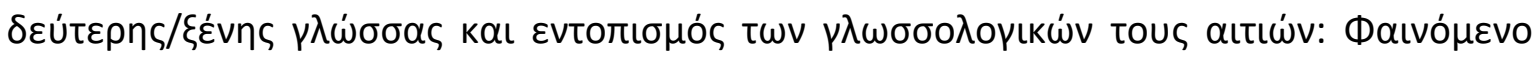

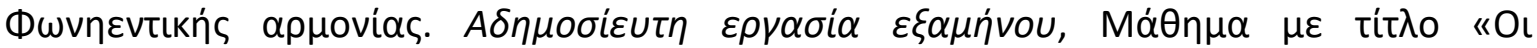

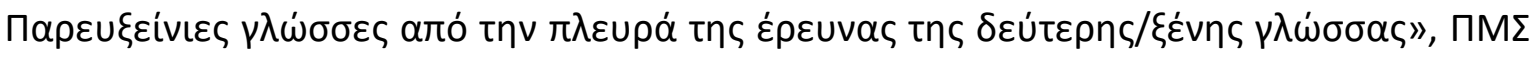

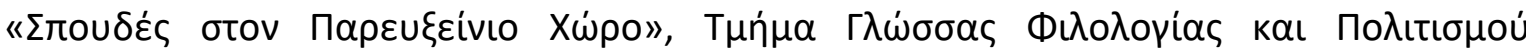

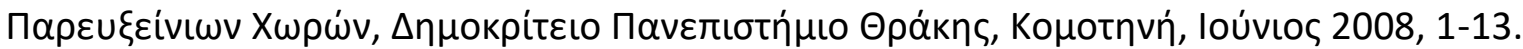


Memiş, A. (2013). "Yabancı Dil Olarak Türkçe Öğretiminde Konuşma Ediminin Kazandırılmasında Karşılaşılan Güçlükler ve Çözümleri". 2. Uluslararası Dil ve Edebiyat Konferansı "Balkanlarda Türkçe", Bildiri Kitabı II, Balaban \& Çağlayan (ed.), 14-16 Kasım 2014, Tiran: 330-342.

Od, Ç. (2013). Erken Yaşta Yabancı Dil Öğretiminde Çizgi Filmlerin Dinlediğini Anlama ve Konuşma Becerilerine Katkısı, International Periodical for The Languages, Literature and History of Turkish or Turkic, 8(10), 499-508.

Prasad, N. (2013). Communicative Language Teaching in 21st Century ESL Classroom. English for Specific Purposes World, 40(14), 1-8.

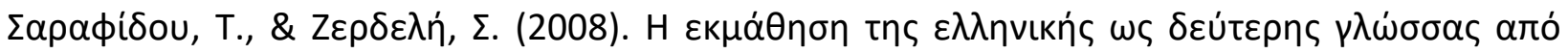

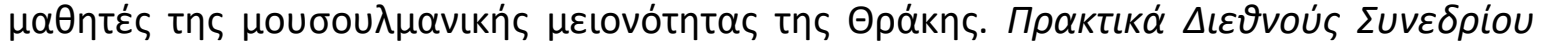

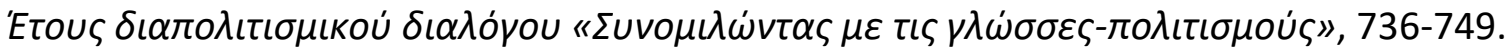

Sharma, P., \& Barrett, B. (2011). Blended Learning: Using technology in and beyond the language classroom. Oxford: Macmillan. 